\title{
Novel aerosol extinction coefficients and lidar ratios over the ocean from CALIPSO-CloudSat: evaluation and global statistics
}

\author{
David Painemal $^{1,2}$, Marian Clayton ${ }^{1,2}$, Richard Ferrare ${ }^{2}$, Sharon Burton ${ }^{2}$, Damien Josset ${ }^{3}$, and Mark Vaughan $^{2}$ \\ ${ }^{1}$ Science Systems and Applications Inc., Hampton, VA 23666, USA \\ ${ }^{2}$ NASA Langley Research Center, Hampton, VA 23666, USA \\ ${ }^{3}$ US Naval Research Laboratory Stennis Space Center, MS 39529, USA
}

Correspondence: David Painemal (david.painemal@nasa.gov)

Received: 15 October 2018 - Discussion started: 6 November 2018

Revised: 13 March 2019 - Accepted: 20 March 2019 - Published: 10 April 2019

\begin{abstract}
Aerosol extinction coefficients $\left(\sigma_{\mathrm{a}}\right)$ and lidar ratios (LRs) are retrieved over the ocean from CALIPSO's CloudAerosol Lidar with Orthogonal Polarization (CALIOP) attenuated backscatter profiles by solving the lidar equation constrained with aerosol optical depths (AODs) derived by applying the Synergized Optical Depth of Aerosols (SODA) algorithm to ocean surface returns measured by CALIOP and CloudSat's Cloud Profiling Radar. $\sigma_{\mathrm{a}}$ and LR are retrieved for two independent scenarios that require somewhat different assumptions: (a) a single homogeneous atmospheric layer (1L) for which the LR is constant with height and (b) a vertically homogeneous layer with a constant LR overlying a marine boundary layer with a homogenous LR fixed at $25 \mathrm{sr}$ (two-layer method, 2L). These new retrievals differ from the standard CALIPSO version 4.1 (V4) product, as the CALIOP-SODA method does not rely on an aerosol classification scheme to select LR. CALIOP-SODA $\sigma_{\mathrm{a}}$ and LR are evaluated using airborne high-spectral-resolution lidar (HSRL) observations over the northwest Atlantic. CALIOPSODA LR (1L and $2 \mathrm{~L}$ ) positively correlates with its HSRL counterpart (linear correlation coefficient $r>0.67$ ), with a negative bias smaller than $17.4 \%$ and a good agreement for $\sigma_{\mathrm{a}}(r \geq 0.78)$ with a small negative bias $(\leq|-9.2 \%|)$. Furthermore, a global comparison of optical depths derived by CALIOP-SODA and CALIPSO V4 reveals substantial discrepancies over regions dominated by dust and smoke (0.24), whereas Aqua's Moderate resolution Imaging Spectroradiometer (MODIS) and SODA AOD regional differences are within 0.06 .

Global maps of CALIOP-SODA LR feature high values over littoral zones, consistent with expectations of continen-
\end{abstract}

tal aerosol transport offshore. In addition, seasonal transitions associated with biomass burning from June to October over the southeast Atlantic are well reproduced by CALIOP_ SODA LR.

\section{Introduction}

Advances in our understanding of the 3-D structure of atmospheric aerosols have been greatly accelerated with the advent of the Cloud-Aerosol Lidar with Orthogonal Polarization (CALIOP), on board the Cloud-Aerosol Lidar and Infrared Pathfinder Satellite Observation (CALIPSO; Winker et al., 2009, 2010, 2013). CALIOP has provided the first global view of aerosol distribution in the boundary layer and free troposphere (Winker et al., 2013), progressed our knowledge of the long-range transport of dust (e.g., Liu et al., 2008; Uno et al., 2011; Yu et al., 2015) and smoke (e.g., de Laat et al., 2012; Das et al., 2017; Khaykin et al., 2018), and facilitated the evaluation of chemical transport models (Nowottnick et al., 2015; Koffi et al., 2016), among many other accomplishments in the area of aerosol and cloud research.

CALIOP estimates aerosol extinction coefficients on a global scale with unprecedented vertical detail. The undetermined problem of solving the lidar equation with two physical unknowns, the aerosol extinction and backscatter coefficients, is addressed in the CALIPSO algorithm by relating both variables via an extinction-to-backscatter ratio, or lidar ratio (LR). This standard technique (e.g., Fernald, 1984) expresses the lidar equation in terms of only one unknown, if LR is prescribed. As aerosol types can be related 
to specific values of lidar ratios (e.g., Müller et al., 2007), the CALIPSO algorithm utilizes predefined LR assigned to a number of aerosol types, which in turn, are identified using the CALIPSO automated aerosol typing algorithm (Omar et al., 2009; Kim et al., 2018). Thus, the quality of CALIOP retrievals will depend on how well the actual lidar ratios match the pre-tabulated values and to what extent the aerosol typing algorithm properly classifies aerosols. Another source of uncertainty is the detectability limits of the CALIPSO algorithm, which prevents retrieving aerosol properties for tenuous aerosol layers (Rogers et al., 2014; Thorsen et al., 2017). For instance, Toth et al. (2018) found that no aerosol was detected within $\sim 71 \%$ of the CALIOP profiles measured during daytime and $\sim 41 \%$ of the nighttime measurements. More aerosol detection during nighttime is explained by the absence of solar background noise, which leads to a significantly better signal-to-noise ratio. The aforementioned factors likely explain discrepancies between CALIOP and other remote-sensing datasets such as those from the Moderate Resolution Imaging Spectroradiometer (MODIS) and AERONET (e.g., Redemann et al., 2012; Schuster et al., 2012).

Uncertainty reduction in the selection of LR can be attained by constraining the lidar equation solution with an independent estimate of aerosol optical depth (AOD). This implies the minimization of the error between the retrieved AOD (estimated from the retrieved extinction coefficient) and the target AOD by iteratively adjusting LR. Burton et al. (2010) utilize AOD from the MODIS instruments on board both Aqua and Terra satellites for estimating aerosol extinction from CALIOP for cases in which AOD exceeds $0.15(0.2)$ over the ocean (land). Similarly, Royer et al. (2010) applied an equivalent method for estimating LR and extinction coefficients over the Po Valley in Italy. Although CALIOP-MODIS retrievals in Burton et al. (2010) tend to compare better with airborne measurements relative to the CALIPSO standard product (version 2), MODIS AOD is limited to daytime, and MODIS and CALIOP differ in their along-track spatial resolution. These previous studies have proven the value of counting on independent CALIOP retrievals for evaluating CALIPSO's standard data products.

In this contribution, we present a new method in which CALIOP-based lidar ratios and aerosol extinction coefficients over the nonpolar oceans are obtained by constraining the retrievals with AOD derived from cross-calibrated CALIOP and CloudSat Cloud Profiling Radar (CPR) surface echos, using the Synergized Optical Depth of Aerosols (SODA) product (Josset et al., 2008). SODA AOD is a suitable dataset, as it is collocated with CALIOP by definition and retrievals are possible during both daytime and nighttime for the period 2006-2011. After November 2011 SODA is only available for daytime, as CloudSat has operated in daylight-only operation mode to conserve power (Gravseth and Piepe, 2013). Our goal is to provide an independent CALIOP dataset that can be used for evaluating specific as- pects of the CALIPSO Science Team product, as well as for investigating aerosol-related topics in climate research. We first summarize the algorithm and evaluate the new retrievals against state-of-the-art aerosol observations from the NASA Langley airborne High Spectral Resolution Lidar (HSRL, Sects. 3 and 4). Next, we compare the CALIOP-SODA extinction coefficient and AOD with their CALIPSO Science Team version 4 counterparts. Lastly, we present global maps of lidar ratio and marine boundary layer aerosol optical depth, and provide a physical interpretation for the regional patterns derived from CALIOP-SODA.

\section{Dataset}

\subsection{CALIOP}

Version 4.1 (V4) CALIOP elastic backscatter lidar measurements at 532 and $1064 \mathrm{~nm}$ are utilized in this work. For the derivation of CALIOP-SODA retrievals, we use Level 1 lidar attenuated backscatter and the Level 2 Vertical Feature Mask product, with a $333 \mathrm{~m}$ horizontal resolution below $8.2 \mathrm{~km}$. CALIOP V4 aerosol extinction coefficients and AOD estimates are taken from the Level 2 aerosol profile product at $5 \mathrm{~km}$ horizontal resolution. To reduce ambiguities in the CALIOP aerosol classification scheme, we restrict the analysis to samples with cloud-aerosol discrimination (CAD) scores higher than $|50|$, equivalent to at least medium confidence in the CALIOP layer classification (Liu et al., 2019).

For comparing CALIOP-SODA and V4 products, we follow the procedure outlined in Koffi et al. (2016): where the vertical feature mask (VFM) feature classification flags indicate regions of clear air, we set the corresponding extinction coefficients to zero. While these regions are labeled as "clear air", they are simultaneously assumed to be populated by highly diffuse aerosols that lie well below the CALIOP layer detection threshold. Typically, the detection threshold is range dependent, and varies as a function of molecular density, solar background and other instrument noise, and signal averaging (Vaughan et al., 2009). In terms of AOD, global analysis of CALIOP V3 daytime data by Toth et al. (2018) show that the "aerosol-free" columns reported by the CALIOP algorithm correspond to a mean MODIS AOD of 0.03-0.05. A similar analysis by Kim et al. (2017) shows that, as expected, CALIPSO extinction and AOD retrieval capabilities are substantially better at night than during the day. These authors estimate a maximum mean undetected extinction coefficient of $\sim 0.006 \mathrm{~km}^{-1}$ during daytime versus $\sim 0.003 \mathrm{~km}^{-1}$ at night (see their Fig. 5c).

\subsection{SODA aerosol optical depth}

SODA uses the relationship between CALIOP (532 and $1064 \mathrm{~nm})$ and CPR $(3.1 \mathrm{~mm}, 94 \mathrm{GHz})$ surface return signals, along with a correction for the atmospheric transmission at the radar wavelength, to derive AOD at the lidar 
wavelengths. In short, SODA estimates of AOD rely on the radar-to-lidar ocean surface scattering cross-calibration for cloud-free columns (Josset et al., 2008, 2010). Consequently, SODA can provide a cloud-free AOD without having to rely on an accurate assignment of a particular aerosol type with an appropriate lidar ratio. In addition, the algorithm does not depend on predetermined aerosol models with specific particle size distributions and refractive indexes, unlike MODIS. SODA AOD version 2, based on CALIPSO version 3 (V3), is developed at the ICARE data and services center (http: //www.icare.univ-lille1.fr, last access: 27 December 2017) in Lille (France) under the auspices of the CALIPSO mission and supported by the French National Centre for Space Studies (CNES). Josset et al. (2013) estimate a systematic error in SODA AOD of 0.015 and 0.059 , respectively, for nighttime and daytime AOD. In addition, good agreement between SODA and MODIS has been reported in Josset et al. (2010, 2015), with a correlation coefficient $>0.89$ and a mean difference of 0.003 , while Dawson et al. (2015) report a root-mean-square error of 0.03 between SODA and AERONET AOD and $r=0.59$ for AERONET sites near the coast. Further, we also evaluate SODA AOD with HSRL data in Sect. 4, and compare SODA and MODIS AOD over the global ocean in Sect. 6. While $1064 \mathrm{~nm}$ SODA AOD is also utilized in this study, caution needs to be exercised when using the $1064 \mathrm{~nm}$ SODA data due to calibration uncertainties in CALIPSO V3 (Vaughan et al., 2010).

\subsection{HSRL}

CALIOP retrievals are evaluated against airborne measurements by the NASA Langley High Spectral Resolution Lidar (HSRL; Hair et al., 2008) at $532 \mathrm{~nm}$. The instrument allows for the independent determination of aerosol extinction and backscatter coefficients at $532 \mathrm{~nm}$ (and thus lidar ratio) using the HSRL technique (Eloranta, 2005). HSRL $532 \mathrm{~nm}$ AOD and aerosol extinction coefficients have been regularly validated against other airborne instruments, with biases less than $6 \%$ and $3 \%$, respectively (Rogers et al., 2009), and generally to within 0.03 in comparison with AERONET AOD (Sawamura et al., 2017). The AOD product from the HSRL instrument makes use of the molecular channel, which is a direct observation of atmospheric attenuation between the aircraft and the surface when compared against the GEOS5 molecular density profile (Rogers et al., 2009). Since this method requires no assumptions about the lidar ratio or assumptions that the lidar ratio is constant, it provides a useful truth measurement in the context of this study.

As HSRL measurements at $1064 \mathrm{~nm}$ are limited to attenuated backscatter, similar to CALIOP, only $532 \mathrm{~nm}$ HSRL retrievals will be utilized in this study. The data used in this study were acquired 11-27 August 2010 while the HSRL conducted a dedicated CALIPSO validation campaign over the Caribbean Sea (Burton et al., 2013; Rogers et al., 2014). As required for all HSRL-CALIPSO validation measure- ments, the HSRL flight paths during this campaign were spatially matched with coincident CALIPSO ground tracks (Rogers et al., 2014).

\section{Derivation of aerosol extinction coefficient and lidar ratio}

The method for deriving aerosol extinction coefficient $\left(\sigma_{\mathrm{a}}\right)$ and lidar ratio (LR) is based on Fernald (1984) applied to the CALIOP attenuated backscatter, and is briefly summarized in the following. For CALIOP, the lidar equation is expressed in terms of height $z$ (range) as

$$
\begin{aligned}
\beta_{\text {att }}(z) & =\left(\beta_{\mathrm{m}}(z)+\beta_{\mathrm{a}}(z)\right) \\
& \cdot \exp \left(-2 \int_{0}^{z}\left(\sigma_{\mathrm{m}}\left(z^{\prime}\right)+\sigma_{\mathrm{a}}\left(z^{\prime}\right)\right) \mathrm{d} z^{\prime}\right) .
\end{aligned}
$$

Here $\beta_{\text {att }}$ corresponds to the CALIOP total attenuated backscattering cross section, $\beta_{\mathrm{m}}$ and $\beta_{\mathrm{a}}$ denote the molecular ("m") and aerosol ("a") backscatter coefficients, and $\sigma_{\mathrm{m}}$ and $\sigma_{\mathrm{a}}$ are the molecular and aerosol extinction coefficients. Since the molecular contribution can be accurately estimated using atmospheric profiles from numerical weather models, the two unknowns are $\beta_{\mathrm{a}}(z)$ and $\sigma_{\mathrm{a}}(z)$. Equation (1) can be reduced to one unknown by relating extinction and backscatter coefficient via their lidar ratio, that is

$\operatorname{LR}(z)=\frac{\sigma_{\mathrm{a}}(z)}{\beta_{\mathrm{a}}(z)}$.

It follows that Eq. (1) can be expressed in terms of LR and $\beta_{\mathrm{m}}$ as

$$
\begin{aligned}
\beta_{\text {att }}(Z) & =\left(\beta_{\mathrm{m}}(z)+\beta_{\mathrm{a}}(z)\right) \\
& \cdot \exp \left(-2 \int_{0}^{z}\left(\sigma_{\mathrm{m}}\left(z^{\prime}\right)+\mathrm{LR}\left(z^{\prime}\right) \cdot \beta_{\mathrm{a}}\left(z^{\prime}\right)\right) \mathrm{d} z^{\prime}\right) .
\end{aligned}
$$

The conventional method to solve Eq. (3) follows Fernald (1984) and consists of iteratively solving for $\beta_{\mathrm{a}}$, assuming a functional form of the lidar ratio $\operatorname{LR}(z)$. The LR selection is physically constrained by comparing the retrieved aerosol optical depth $\left(\mathrm{AOD}_{\text {ret }}=\int_{0}^{z} \sigma_{\mathrm{a}}\left(z^{\prime}\right) \mathrm{d} z^{\prime}\right)$ with SODA

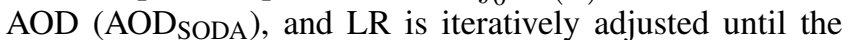
retrieved AOD matches the SODA AOD to within 0.001 or less (i.e., when $\left|\mathrm{AOD}_{\text {ret }}-\mathrm{AOD}_{\mathrm{SODA}}\right| \leq 0.001$ ). While the distribution of LR with height can be specified in different ways (e.g., Ansmann, 2006), here we opt for two assumptions, which in turn yield two independent sets of aerosol extinction and lidar ratio retrievals.

1. One-layer lidar ratio ( $I L R)$. The simplest assumption is to consider one constant lidar ratio with height. This method is expected to perform well for atmospheric profiles characterized by only one aerosol type. 
2. Two-layer lidar ratio (2LR). We also consider an additional scenario, which consists of treating the atmospheric column as two layers, that is, the marine atmospheric boundary layer (MBL) and a second aerosol layer of as-yet-undetermined composition. This method is intended to better capture specific events with two predominant aerosol types, particularly smoke over marine aerosols and dust over marine aerosols, which are particularly frequent over the Atlantic Ocean. The LR for the MBL is assumed constant at $25 \mathrm{sr}$, as suggested by HSRL measurements over the ocean (Burton et al., 2012, 2013). This lidar ratio is slightly higher than the value of $23 \mathrm{sr}$ assumed by Kim et al. (2018) and $18 \pm 5 \mathrm{sr}$ reported by Groß et al. (2013) at Cabo Verde $\left(14.9^{\circ} \mathrm{N}\right.$, 23.5 $\left.{ }^{\circ} \mathrm{W}\right)$. In contrast, $532 \mathrm{~nm}$ Raman lidar observations at Barbados $\left(13^{\circ} \mathrm{N}, 59^{\circ} \mathrm{W}\right)$ encompass MBL lidar ratios between 21 and $35 \mathrm{sr}$, with magnitudes primarily controlled by free tropospheric intrusions of dust (Groß et al., 2015) and the environmental relative humidity (Haaring et al., 2017). A similar range of MBL lidar ratios was observed in the eastern Atlantic by Bohlmann et al. (2018), with values modulated by the presence of dust-smoke aerosols. Without a priori knowledge of the MBL lidar ratio, the value prescribed here $(25 \mathrm{sr})$ is within the range reported in previous studies over the ocean. $\sigma_{\mathrm{a}}(z)$ and the upper-layer LR are iteratively calculated using the Fernald method with the constraint provided by $\mathrm{AOD}_{\mathrm{SODA}}$, and $\mathrm{LR}=25 \mathrm{sr}$ in MBL. MBL height is computed by applying the bulk Richardson number method (McGraw-Spangler and Molod, 2014).

The CALIOP attenuated backscatter $\left(\beta_{\text {att }}\right)$ at $333 \mathrm{~m}$ resolution is taken from the Level 1 CALIPSO product and averaged to achieve a $1 \mathrm{~km}$ along-track resolution. Similarly, SODA AOD retrieved at $333 \mathrm{~m}$ is averaged to $1 \mathrm{~km}$ resolution. In addition, the feature classification mask product is utilized for identifying cloudy pixels and cases with fully attenuated signal, in which CALIOP-SODA retrievals are not possible. The molecular components in Eq. (3) are derived from the Goddard Earth Observing System Model version 5 (GEOS-5), with $\beta_{\mathrm{m}}$ estimated as a function of air density, and the effect of ozone attenuation in $\sigma_{\mathrm{m}}$ is accounted for following Vaughan et al. (2005). Lastly, MBL height for the 2LR method is also computed from GEOS-5.

\section{CALIOP-SODA evaluation with airborne HSRL measurements}

CALIOP-SODA retrievals of aerosol extinction coefficient, lidar ratio and AOD are evaluated using eight flights during August 2010 over the western Atlantic, for the domain bounded by $70-55^{\circ} \mathrm{W}$ and $13-35^{\circ} \mathrm{N}$ (Fig. 1a). CALIOPSODA is spatially averaged to match the nominal $5 \mathrm{~km}$ horizontal resolution of CALIPSO V4, and only samples with $5 \mathrm{~km}$ cloud-free scenes are retained. Both CALIPSO V4 and
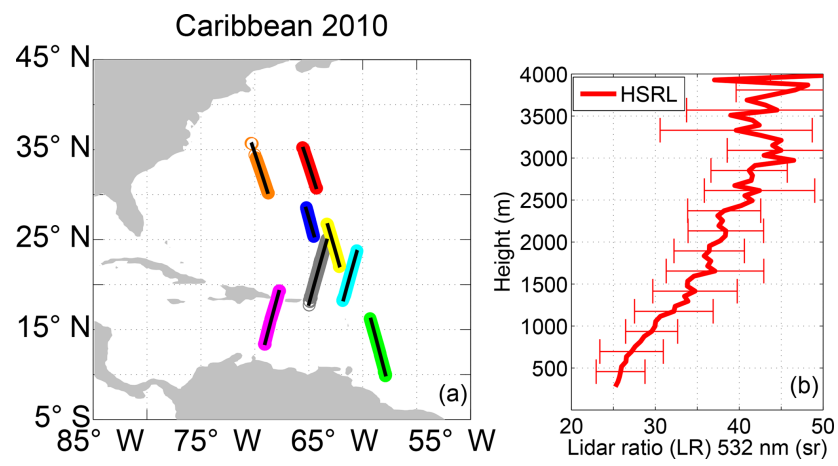

Figure 1. (a) Flight tracks during the 2010 field campaign (colored for individual flight missions). Black solid lines correspond to the matched CALIPSO tracks. (b) Mean HSRL lidar ratio (532 nm) as a function of altitude and 1 standard deviation (error bar) for all the flight tracks in Fig. 1a.

CALIOP-SODA are then spatially collocated with the aircraft track (Fig. 1) for samples with a temporal mismatch of less than $90 \mathrm{~min}$ (Rogers et al., 2014). Lastly, satellite and airborne observations are spatially averaged to a common $0.2^{\circ}$ resolution (in latitude). It is worth noting that although the CALIOP V4 data products are reported at a uniform horizontal resolution of $5 \mathrm{~km}$, in reality, larger spatial averaging of the lidar signal is required $(20$ or $80 \mathrm{~km})$ for tenuous aerosol layers to increase the aerosol layer detectability in the CALIPSO aerosol classification scheme. Thus, the use of a $0.2^{\circ}$ horizontal average for comparing airborne and satellite observations is adequate when considering possible spatial averaging of the CALIOP V4 retrievals. Approximately 42 and $460.2^{\circ}$ samples were collocated with HSRL (CALIOPSODA and CALIOP, respectively).

The HSRL measurements during Caribbean 2010 were characterized by the presence of dust, dust mixed with maritime aerosols and continental pollution; the occurrence of pure maritime aerosols was confined to the boundary layer (Burton et al., 2013). This aerosol typing is manifested in a lidar ratio of $25 \mathrm{sr}$ below $500 \mathrm{~m}$ and a linear increase with height that reaches values of $40-45 \mathrm{sr}$ in the free troposphere (Fig. 1b). These measurements also provide support for the use of a lidar ratio of $25 \mathrm{sr}$ in the boundary layer for the $2 \mathrm{~L}$ method. Before evaluating aerosol extinction coefficients and lidar ratios, we compare SODA AODs and CALIOP V4 AODs against their HSRL counterparts (Fig. 2a). In general, both CALIOP-based retrievals correlate well with the HSRL $(r \geq 0.94)$, with a slightly higher correlation for SODA (and absolute bias between $10 \%$ and $17 \%$ ), with SODA underestimating and CALIOP V4 overestimating AOD. Linear fits of SODA and V4 AOD relative to HSRL (red and blue lines in Fig. 2a) indicate that the SODA bias is relatively constant with AOD, whereas a V4 AOD overestimate tends to increase with AOD especially during nighttime. Nighttime and daytime correlations remain approximately the same for 

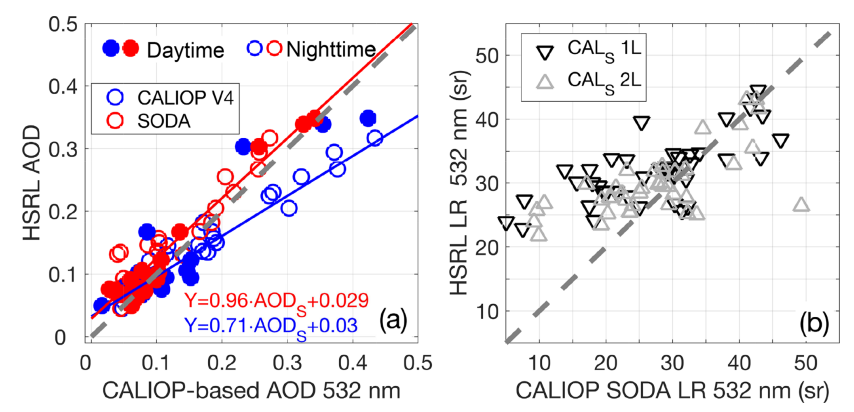

Figure 2. (a) Scatterplot between SODA (red) and CALIPSO V4 (blue) against HSRL AOD at $532 \mathrm{~nm}$. Filled and open circles indicate daytime and nighttime observations, respectively. Blue and red lines (and equations) are the linear fit for V4 and SODA AOD $\left(\mathrm{AOD}_{\mathrm{v} 4}\right.$ and $\left.\mathrm{AOD}_{\mathrm{S}}\right)$ relative to HSRL. (b) Comparison between CALIPSO-SODA $\left(\mathrm{CAL}_{\mathrm{S}}\right)$ lidar ratio based on the one-layer $(1 \mathrm{~L})$ and two-layer (2L) assumptions with the HSRL column-effective lidar ratio from Eq. (4) (black and gray symbols, respectively). The gray dashed line is the one-to-one relationship.

Table 1. Linear correlation coefficient $(r)$, mean bias and RMSE between HSRL and SODA and CALIOP standard V4 AOD. Percentages are calculated relative to the mean HSRL AOD.

\begin{tabular}{lrrr}
\hline $\begin{array}{l}\text { CALIOP-based } \\
\text { AOD }\end{array}$ & $r$ & Mean bias & RMSE \\
\hline SODA & 0.96 & $-0.024(-17 \%)$ & $0.035(24.2 \%)$ \\
Standard V4 & 0.94 & $0.014(10 \%)$ & $0.044(31.2 \%)$ \\
\hline
\end{tabular}

both CALIOP V4 and SODA. However, V4 linear correlation coefficients for AOD $<0.3$ are slightly lower for daytime $(r=0.78)$ than nighttime $(r=0.94)$, whereas SODA daytime-nighttime correlations for low AOD remain high $(r \geq 0.93)$. The reduced daytime correlation for CALIOP V4 is expected as the reduced signal-to-noise ratio due to the solar background signal hampers the algorithm's ability to detect and classify aerosols. Finally, in terms of the root-meansquare error (RMSE), SODA RMSE (24.2\% relative to the mean) is smaller than that for CALIOP V4 (31.2\%, Table 1$)$.

The evaluation of CALIOP-SODA lidar ratio and aerosol extinction coefficient is summarized in the following. For $\mathrm{LR}$, we use the column-effective lidar ratio (Ansmann, 2006), calculated as

$\mathrm{LR}_{\mathrm{HSRL}}=\frac{\sum_{z=z 0}^{z_{1}} \sigma_{\mathrm{a}}(z)}{\sum_{z=z 0}^{z_{1}} \beta_{\mathrm{a}}(z)}$,

with $z_{1}$ denoting the highest altitude with $\sigma_{\mathrm{a}}$ HSRL retrievals $(\sim 6.5 \mathrm{~km})$. For evaluating CALIOP-SODA 1L LR, LR $_{\text {HSRL }}$ in Eq. (4) is estimated using the last range bin above the ocean surface $(37.8 \mathrm{~m})$ as the lower bound, $z_{0}$. In addition, the comparison between CALIPSO-SODA 2L LR
Table 2. As in Table 1 but for CALIOP-SODA lidar ratio.

\begin{tabular}{lrrr}
\hline $\begin{array}{l}\text { CALIOP-SODA } \\
\text { LR }\end{array}$ & $r$ & Mean bias & RMSE \\
\hline One layer (1L) & 0.67 & $-2.5 \mathrm{sr}(-8.1 \%)$ & $7.4 \mathrm{sr}(27.1 . \%)$ \\
Two layers (2L) & 0.72 & $-4.7 \mathrm{sr}(-17.4 \%)$ & $8.7 \mathrm{sr}(32.0 \%)$ \\
\hline
\end{tabular}

and $\mathrm{LR}_{\mathrm{HSRL}}$ is performed by recomputing $\mathrm{LR}_{\mathrm{HSRL}}$ using the MBL height for $z_{0}$ in Eq. (4). Since valid HSRL extinction retrievals are only derived for heights above $270 \mathrm{~m}$ from the surface, we have assumed a constant extinction coefficient for the layer below $270 \mathrm{~m}$, with values taken from the lowest height with available retrievals $(\sim 270 \mathrm{~m})$. The comparison depicted in Fig. 2b yields $r=0.67-0.72$ between both CALIOP-SODA methods (1L and 2L) and HSRL, with a negative mean bias smaller than $17.4 \%$ and RMSE of up to $8.7 \mathrm{sr}$ (Fig. 2b and Table 2).

Mean vertically resolved aerosol extinction coefficients from SODA, CALIOP V4 and HSRL are depicted in Fig. 3a and $\mathrm{b}$ for daytime and nighttime observations, respectively. The agreement between HSRL (red) and CALIOPSODA $1 \mathrm{~L}$ and $2 \mathrm{~L}$ (overlapped gray and black) is remarkable throughout the lower troposphere, with a maximum overestimation of $0.027 \mathrm{~km}^{-1}(50 \%)$ near $500 \mathrm{~m}$. CALIOPSODA $1 \mathrm{~L}$ and $2 \mathrm{~L}$ yield identical results, which is likely the effect of a shallow marine boundary layer $(<500 \mathrm{~m})$. In contrast, CALIOP V4 (blue) consistently overestimates the airborne measurements for heights below $1 \mathrm{~km}$ during both daytime and nighttime, with magnitudes up to $0.102 \mathrm{~km}^{-1}(100 \%)$ relative to the HSRL during nighttime and $0.078 \mathrm{~km}^{-1}(140 \%)$ during the day. This overestimate is explained by the CALIPSO V4 constant lidar ratio of $37 \mathrm{sr}$ for dusty marine aerosol, which is generally higher than the lidar ratio retrieved by both the HSRL and SODA for Caribbean 2010 (Fig. 2b). Interestingly, both CALIOP-SODA and CALIOP V4 correlate well with the HSRL, with correlations around 0.80 (Table 3). The RMSE for CALIOP V4 is also higher than that for CALIOP-SODA, especially below $1 \mathrm{~km}$, with maxima around $0.12 \mathrm{~km}^{-1}(155 \%)$ and $0.06 \mathrm{~km}^{-1}(83 \%)$ for CALIOP V4 and CALIOP-SODA, respectively (Fig. 3c). Aerosol extinction coefficient statistics for the atmospheric column below $3.0 \mathrm{~km}$ (Table 2) corroborate the overall smaller bias and RMSE of CALIOP-SODA relative to V4.

\section{Global analysis}

\subsection{Preliminary comparison between CALIOP-SODA, MODIS and CALIOP-V4 AOD}

A total of 5 months of collocated SODA, CALIOP V4 Level 2 and Aqua MODIS data during June-October 2010 were compared over nonpolar oceanic regions with the goal of 

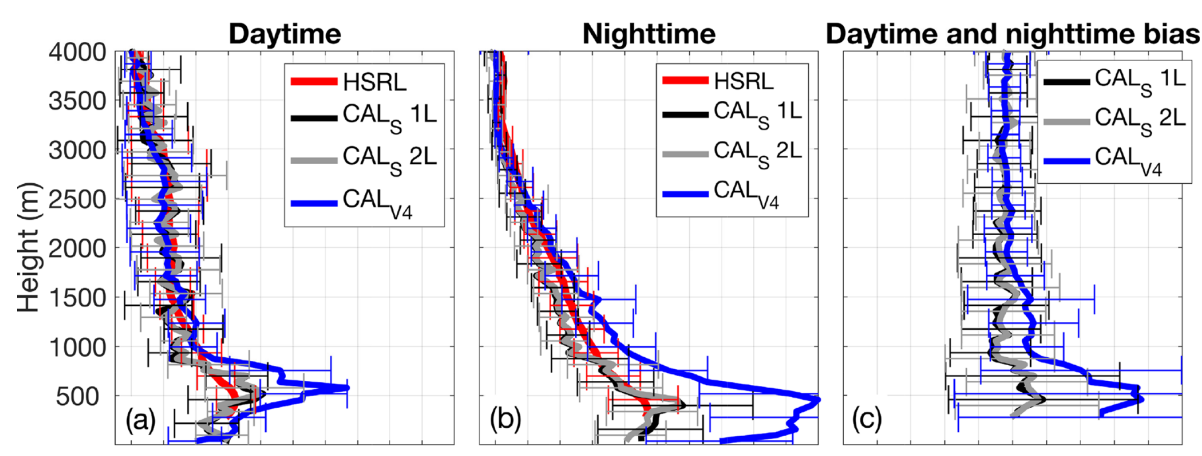

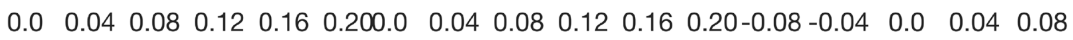

Extinction $(\sigma) 532 \mathrm{~nm}(1 / \mathrm{km})$ Extinction $(\sigma) 532 \mathrm{~nm}(1 / \mathrm{km}) \quad$ CAL-HSRL $\sigma(1 / \mathrm{km})$

Figure 3. Mean aerosol extinction coefficient profile from the HSRL (red), CALIPSO-SODA 1L (black), 2L (gray) and the CALIPSO standard V4 product (blue) during (a) daytime and (b) nighttime. (c) Total mean bias of CALIPSO-based extinction relative to the HSRL: CALIPSO-SODA 1L (black) and 2L (gray); CALIPSO V4 (blue). Error bars in Fig. 3a and b denote 1 standard deviation, and RMSE is shown in Fig. 3c.

Table 3. As in Table 1 but for V4 and SODA aerosol extinction coefficient in the lower troposphere (below $3.0 \mathrm{~km}$ ).

\begin{tabular}{lrrr}
\hline CALIOP-based extinction & $r$ & Mean bias & RMSE \\
\hline CALIOP V4 & 0.82 & $0.013 \mathrm{~km}^{-1}(33.0 \%)$ & $0.043 \mathrm{~km}^{-1}(106.0 \%)$ \\
SODA one layer (1L) & 0.78 & $-0.0037 \mathrm{~km}^{-1}(-9.2 \%)$ & $0.028 \mathrm{~km}^{-1}(72.6 \%)$ \\
SODA two layers (2L) & 0.79 & $-0.0029 \mathrm{~km}^{-1}(-7.0 \%)$ & $0.028 \mathrm{~km}^{-1}(73.8 \%)$ \\
\hline
\end{tabular}

identifying the main differences in aerosol extinction coefficient profiles. These months were selected because of the high global climatological AOD observed over the ocean by CALIOP (e.g., Yu et al., 2010). We first averaged $1 \mathrm{~km}$ CALIOP-SODA to the V4 Level 2 nominal resolution $(5 \mathrm{~km})$ and only samples with $5 \mathrm{~km}$ cloud-free scenes are utilized. This is intended to minimize the potential effect of overcast scenes in the retrievals and aerosol swelling near the cloud edges (Várnai and Marshak, 2011). Then, CALIOP-SODA and CALIOP V4 data were further reduced by averaging the retrievals to a common $25 \mathrm{~km}$ resolution. Cloud cover was derived from the $333 \mathrm{~m}$ Vertical Feature Mask and determined as the ratio between profiles with at least one cloudy feature in the atmospheric column to the total. To circumvent CALIOP's narrow field of view, we calculated the statistics in $6^{\circ} \times 3^{\circ}$ (longitude $\times$ latitude) grids.

We first focus on the AOD difference ( $\triangle \mathrm{AOD}$ ) between CALIOP V4 and SODA at 532 and $1064 \mathrm{~nm}$, for day and nighttime (Fig. 4). Daytime $532 \mathrm{~nm} \triangle$ AOD maps reveal higher V4 AOD than SODA for the northeast Atlantic (NEA) and the Indian Ocean (IO), whereas V4 AOD is smaller than SODA over the southeast Atlantic (SEA) and over vast regions of the open ocean. These differences are similar to those observed between CALIOP V3 and MODIS (Redemann et al., 2012). Overall, nighttime differences in $532 \mathrm{~nm}$ AOD appear to diminish, especially for the SEA and the northwest Pacific (NWP), while the positive $\triangle \mathrm{AOD}$ remains high over the IO and NEA.
To verify that SODA-CALIPSO V4 differences are mainly attributed to CALIPSO V4 biases, we perform an additional comparison using Aqua MODIS Level $2550 \mathrm{~nm}$ AOD (MYD04_3K product), taken from the latest Collection 6.1 (Levy et al., 2013) for the June to October period of 2010. Cloud-free $3 \mathrm{~km}$ MODIS AOD pixels are collocated with the CALIPSO track and averaged to approximately $25 \mathrm{~km}$ (along track) to match the averaged $25 \mathrm{~km}$ SODA retrievals. Next, MODIS-SODA mean differences are averaged every $6^{\circ} \times 3^{\circ}$ grid, and depicted in Fig. 5. The MODIS-SODA differences in Fig. 5 are typically within the \pm 0.06 range. Although $\triangle$ AOD reaches up to 0.12 over the Indian Ocean, these differences are smaller than those between CALIPSO V4 and SODA (Fig. 4a). Overall, MODIS further corroborates that CALIPSO V4 AOD is biased low over regions dominated by smoke and biased high for regions with dust. We note that the plausible oceanic CALIOP V4 bias dependence on aerosol types suggested in our study might not be applicable over land, where AOD for dust is underestimated by CALIPSO (e.g., Schuster et al., 2012).

We also show $\triangle$ AOD for the $1064 \mathrm{~nm}$ channel in Fig. 4c, d. The largest $\triangle \mathrm{AOD}$ values are mostly confined to the NEA and IO domains, with higher values for CALIPSO V4 AOD and similar $\triangle \mathrm{AOD}$ during daytime and nighttime. 
(a) Daytime CALIOP V4 - SODA
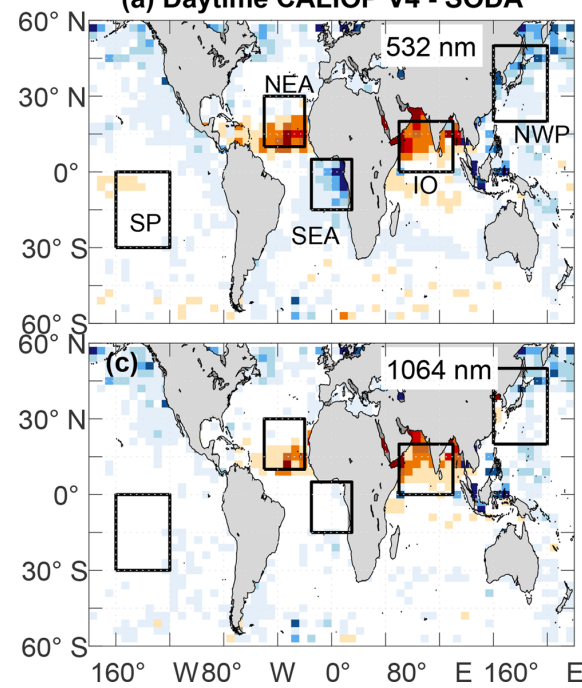

(b) Nighttime CALIOP V4 - SODA $\triangle A O D$

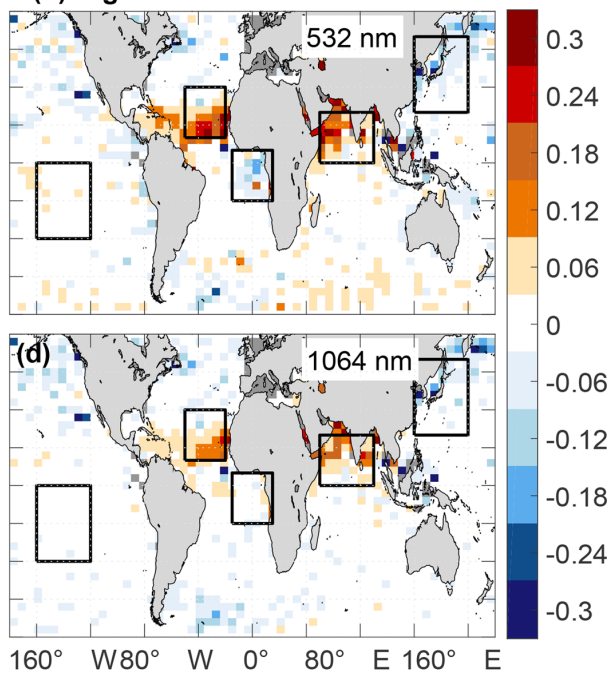

Figure 4. Mean AOD difference between CALIOP V4 and SODA for 5 months of 2010 for daytime (a, c) and nighttime (b, d) and the $532 \mathrm{~nm}(\mathbf{a}, \mathbf{b})$ and $1064 \mathrm{~nm}(\mathbf{c}, \mathbf{d})$ channels. Boxes denote specific regions in which the extinction coefficient profiles are further compared in Fig. 5: South Pacific (SP), southeast Atlantic (SEA), Indian Ocean (IO), northeast Atlantic (NEA) and northwest Pacific (NWP).

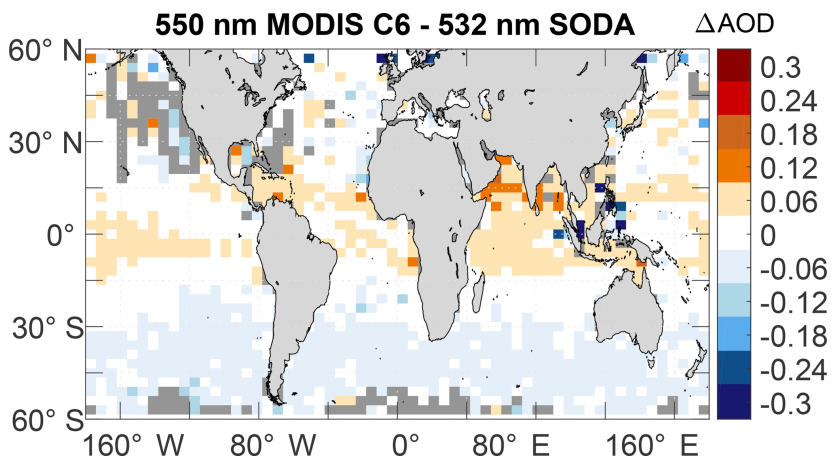

Figure 5. Mean AOD difference between matched $550 \mathrm{~nm}$ MODIS C6 and $532 \mathrm{~nm}$ SODA daytime AOD for 5 months of 2010. Oceanic regions with no available MODIS samples that meet the matching criteria are depicted in dark gray.

\subsection{CALIOP-SODA and CALIOP V4 aerosol extinction profiles}

Matched CALIOP-SODA and CALIOP V4 mean vertical profiles of aerosol extinctions over the regions defined in Fig. 4 (black boxes) are shown in Figs. 6 and 7, for the 532 and $1064 \mathrm{~nm}$ channels, respectively. The main differences, in agreement in AOD differences in Fig. 4, are found: (a) over the IO and NEA where CALIPSO V4 extinction profiles are higher than CALIOP-SODA, and (b) over SEA, with lower V4 extinctions than CALIOP-SODA. Even though the main V4-SODA differences in extinction decrease during nighttime, especially over the SEA, the nighttime differences for the NEA and IO remain nearly the same. Interestingly, the higher CALIOP V4 extinction for the NEA and IO resembles the CALIPSO V4 overestimation during Caribbean 2010 (Fig. 3). CALIOP-SODA and V4 profile differences are modest for regions with small AOD differences, such as the South Pacific (SP) and the northwest Pacific (NWP). Another interesting aspect is the generally higher variability of daytime CALIPSO V4 relative to SODA, manifested in the high standard deviations in Fig. 6 (error bars). This indicates that SODA retrievals are more stable than CALIPSO V4, especially during the daytime, due to the AOD constraint. Moreover, the high solar background substantially degrades CALIPSO aerosol detection capabilities, affecting the retrieved extinction. Lastly, CALIOP-SODA differences between $1 \mathrm{~L}$ and $2 \mathrm{~L}$ are small and typically confined to a layer below $700 \mathrm{~m}$, where $2 \mathrm{~L}$ tends to be smaller than $1 \mathrm{~L}$. This is explained, as in Sect. 4, by a relatively shallow mixed-layer height $(<500 \mathrm{~m})$, where $\mathrm{LR}=25 \mathrm{sr}$ for the $2 \mathrm{~L}$ method.

For completeness, in Fig. 7 we show the aerosol extinction profiles for the $1064 \mathrm{~nm}$ channel. CALIOP-SODA and $\mathrm{V} 4$ profiles yield smaller differences relative to their $532 \mathrm{~nm}$ counterpart, in agreement with $\triangle \mathrm{AOD}$ (Fig. 4).

\subsection{Maps of CALIOP-SODA lidar ratio (LR) at $532 \mathrm{~nm}$}

The number of $25 \mathrm{~km}$ samples utilized in the following SODA LR analysis is depicted in Fig. 8. The extratropical regions yield the smallest number of samples $(<80)$, whereas the occurrence of clear-sky scenes is the highest over subtropical open ocean, with $\sim 400$ retrievals (note that approximately at least eight $1 \mathrm{~km}$ samples are contained in one $25 \mathrm{~km}$ averaged sample with cloud fraction $<67 \%$ ). During nighttime, the number substantially decreases due to the cloud diurnal cycle. Figures 9 and 10 depict global maps of $532 \mathrm{~nm}$ 

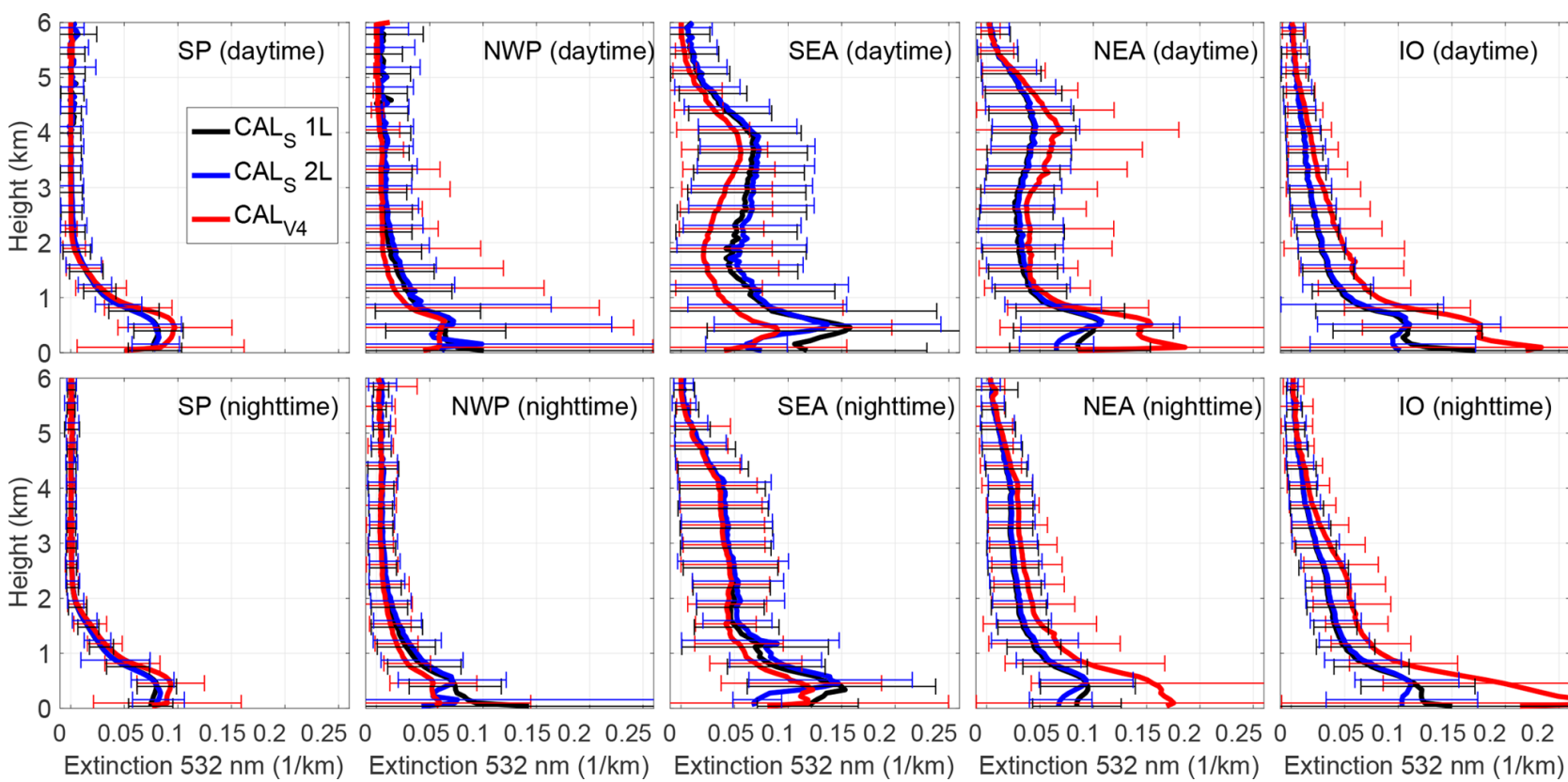

$0.050 .10 .150 .2 \quad 0.25$

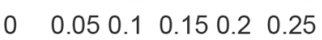

Extinction $532 \mathrm{~nm}(1 / \mathrm{km})$

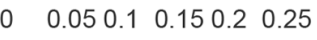

Extinction $532 \mathrm{~nm}(1 / \mathrm{km})$

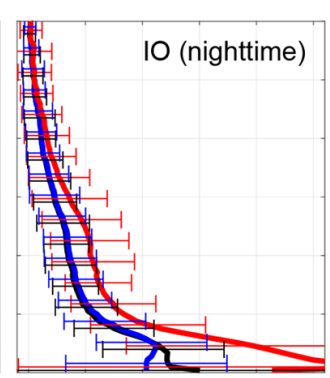

$0.050 .10 .150 .2 \quad 0.25$

Figure 6. Mean aerosol extinction coefficient at $532 \mathrm{~nm}$ for the five regions defined in Fig. 4. Upper and lower panels correspond to daytime and nighttime retrievals. CALIPSO-SODA profiles are in black (1L) and blue (2L), and CALIPSO V4 is in red.
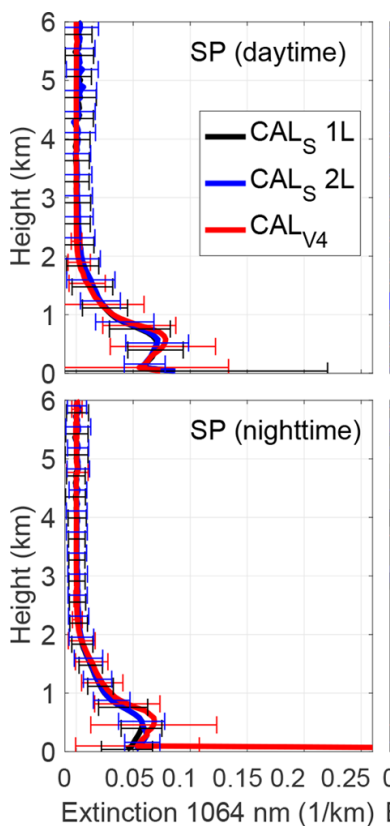
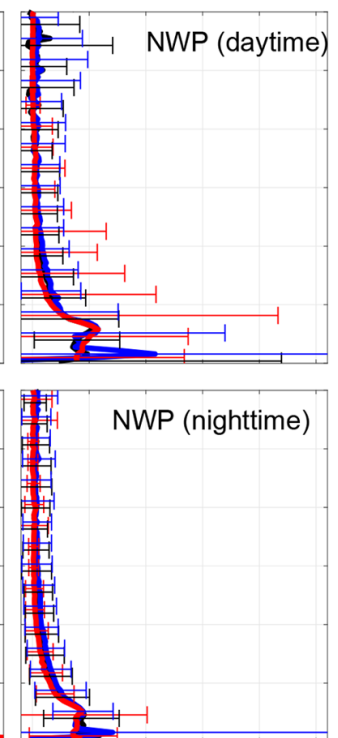
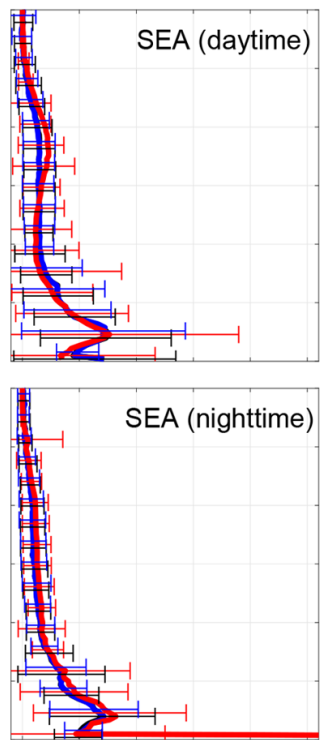
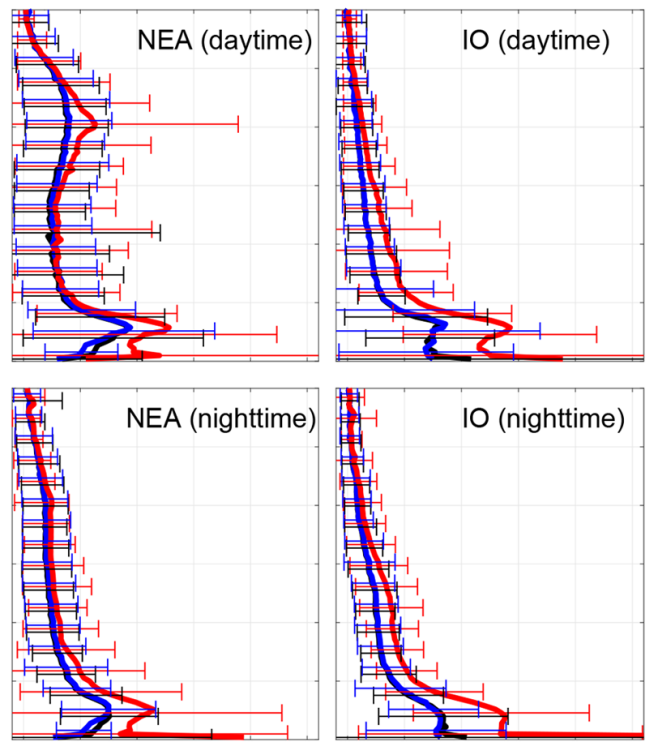

Extinction $1064 \mathrm{~nm}(1 / \mathrm{km})$ Extinction $1064 \mathrm{~nm}(1 / \mathrm{km})$ Extinction $1064 \mathrm{~nm}(1 / \mathrm{km})$ Extinction $1064 \mathrm{~nm}(1 / \mathrm{km})$

LR derived from the $1 \mathrm{~L}\left(\mathrm{LR}_{1 \mathrm{~L}}\right)$ and $2 \mathrm{~L}\left(\mathrm{LR}_{2 \mathrm{~L}}\right)$ assumptions, temporally averaged from March to August (MAMJJA, boreal spring-summer) and September to February (SONDJF, boreal autumn-winter) of 2010 from the $25 \mathrm{~km}$ averaged retrievals with cloud fraction less than $67 \%$. Daytime $532 \mathrm{~nm}$ LR exhibits a clear spatial pattern with high values ( $>45 \mathrm{sr}$ ) in coastal regions, especially off the southwestern African coast. The lowest values are observed over the western and central equatorial Pacific, with ratios less than $30 \mathrm{sr}$, which are typical of clean maritime environments (e.g., Burton et al., 2013). Semiannual transitions are primarily found near the continents, namely, the southeast Atlantic, Mediterranean Sea, Indian Ocean and off the coast of eastern Asia. Nighttime LRs (Fig. 10) are similar to their daytime counterparts, 

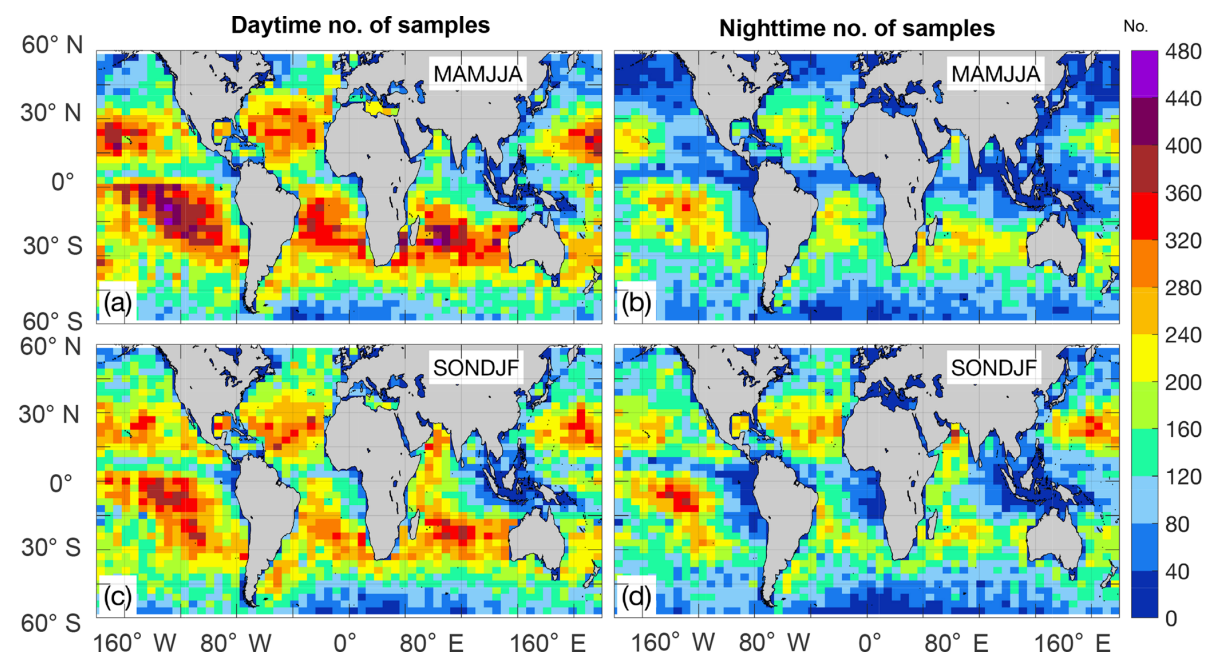

Figure 8. Number of $25 \mathrm{~km}$ CALIOP-SODA samples contained in each semiannual average: (a) daytime MAMJJA, (b) nighttime MAMJJA, (c) daytime SONDJF and (d) nighttime SONDJF.
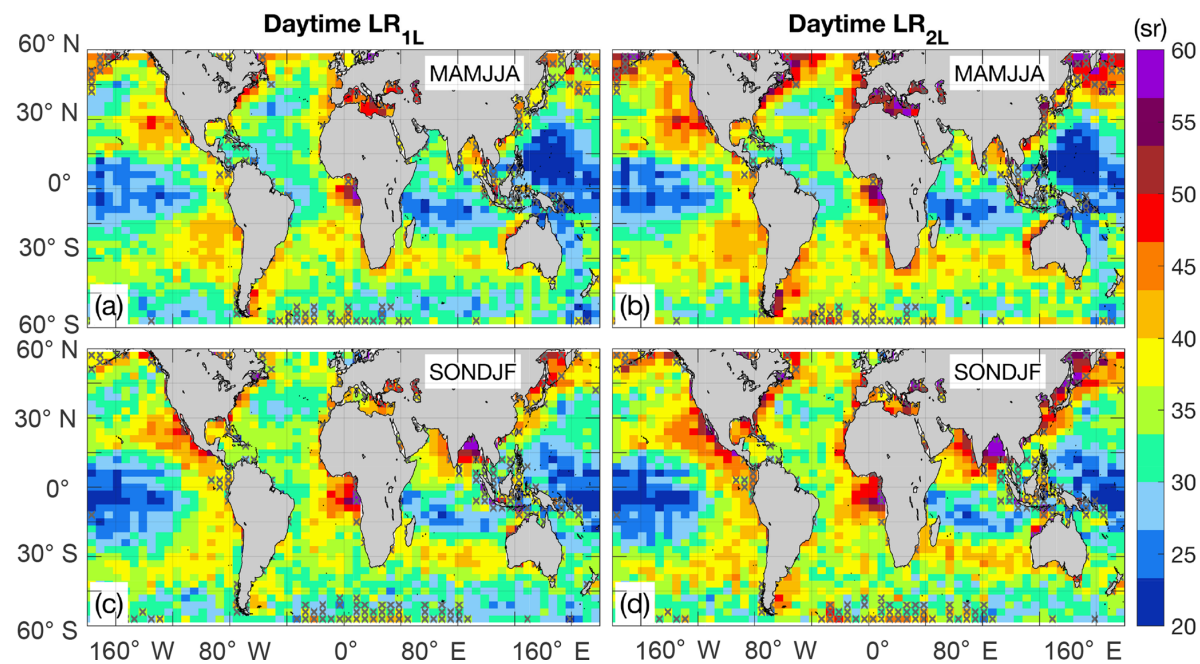

Figure 9. Semiannual daytime $532 \mathrm{~nm}$ lidar ratios. (a) $\mathrm{LR}_{1 \mathrm{~L}}$ for spring-summer, (b) $\mathrm{LR}_{2 \mathrm{~L}}$ for spring-summer, (c) $\mathrm{LR}_{1 \mathrm{~L}}$ for autumn-winter and (d) $\mathrm{LR}_{2 \mathrm{~L}}$ for autumn-winter. Gray crosses indicate regions where less than $15 \%$ of the maximum observable number of samples contribute to the average.

but with slightly higher values and a rather heterogeneous pattern, attributed to the reduced cloud-free sampling at night due to the increased cloud cover, especially over subtropical regions and the Southern Ocean (Fig. $8 \mathrm{~b}$ and d), where stratiform and shallow cumulus clouds are abundant.

Comparing the two-layer assumptions, $\mathrm{LR}_{2 \mathrm{~L}}$ (Fig. $9 \mathrm{~b}$ and d) is higher than $\mathrm{LR}_{1 \mathrm{~L}}$, especially for lidar ratios $>40 \mathrm{sr}$. This result is expected, as the prescribed MBL lidar ratio of $25 \mathrm{sr}$ for $2 \mathrm{~L}$ tends to be lower than the lidar ratio for any aerosol type that would be found above the marine boundary layer and therefore lower than the column average or column-effective lidar ratio. Therefore, to match the SODA $\mathrm{AOD}$, the lidar ratio above the MBL in the $2 \mathrm{~L}$ case must be larger than the column-effective value that the $1 \mathrm{~L}$ case derives. Overall, $\mathrm{LR}_{1 \mathrm{~L}}$ and $\mathrm{LR}_{2 \mathrm{~L}}$ differences are relatively small ( $\sim 5 \mathrm{sr}$ ), which, as we will show in the next section, is associated with the shallow MBL height estimated from the bulk Richardson number method and therefore a relatively small fraction of aerosol that is controlled by the assumed marine lidar ratio in the $2 \mathrm{~L}$ method.

\subsection{Fractional CALIOP-SODA AOD at $532 \mathrm{~nm}$ in the marine boundary layer}

CALIOP-SODA aerosol extinctions are further utilized for quantifying AOD in the boundary layer. We first show in Fig. 11 the 2010 semiannual total SODA AOD for daytime (Fig. 11a, c) and nighttime (Fig. 11b, d) CALIPSO over- 

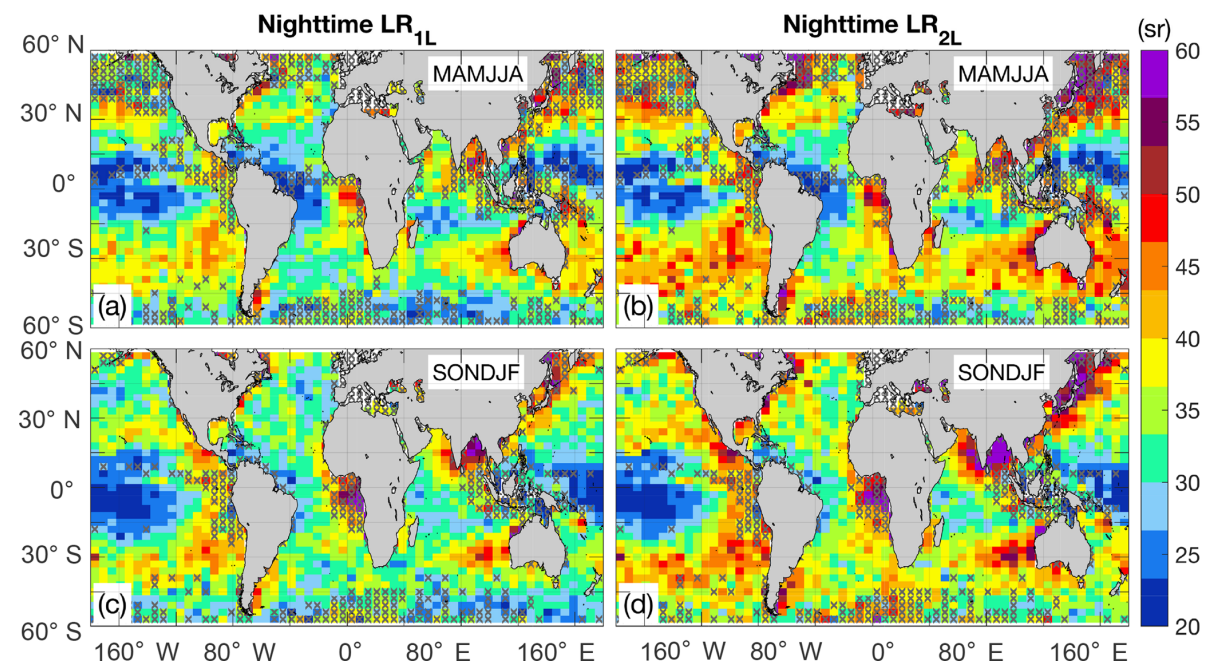

Figure 10. As in Fig. 9 but for nighttime.

passes. Consistent with several studies (e.g., Kittaka et al., 2011; Redemann et al., 2012), high AOD primarily occurs over the eastern Atlantic, in connection with biomass burning and dust emissions from southern and equatorial Africa. A second region of interest encompasses most of the Asian coastal region, where a combination of pollution and dust gives rise to high AOD (Itahashi et al., 2010).

Before presenting MBL AOD, we show the MBL height maps (Fig. 12), with typical heights below $800 \mathrm{~m}$, and littoral maxima up to $1150 \mathrm{~m}$ in northern Africa and Eurasia. Next, we compute MBL AOD by numerically integrating CALIOP-SODA aerosol extinction coefficient from the surface to the MBL height. MBL AOD in Fig. 13 shows a dissimilar pattern relative to its total AOD counterpart (Fig. 11), manifested in a less dominant role of the southeast Atlantic. In addition, coastal Africa, Eurasia and North America exhibit peaks in MBL AOD (>0.12) during boreal springsummer. A second region with high AOD encompasses the extratropical oceans poleward of $45^{\circ} \mathrm{S}-\mathrm{N}$, with a particularly consistent zonal band with high AOD in the Southern Ocean. As expected, 2L MBL AOD is lower than 1L due to the $2 \mathrm{~L}$ assumption of a lidar ratio equal to $25 \mathrm{sr}$ in the MBL. Except for the subtropical ocean, which features shallow MBL and low MBL AOD, a spatial modulation of the marine boundary layer in the MBL AOD is unclear. It is important to mention that estimates of the AOD apportioned in the boundary layer will depend on the MBL dataset utilized in the calculations. An alternative MBL height estimation derived from CALIOP attenuated backscatter (McGrathSpangler and Denning, 2013) yields similar if not higher values than our GEOS-based MBL. However, MBL estimates based on thermodynamical vertical profiles (temperature, relative humidity) from meteorological analyses produce significantly higher MBL (von Engeln and Teixeira, 2013), closely matching the cloud-top height of stratiform and shallow cu- mulus clouds. Thus, the MBL used here is expected to primarily represent the mixed-layer height (von Engeln and Teixeira, 2013).

The fraction of MBL AOD relative to the total is depicted in Fig. 14. The extratropical bands show the highest fraction of MBL AOD, accounting for up to 0.73 (73\%) of the total AOD. Low fractions are found in the subtropics and tropics, with the lowest AOD fraction over the eastern Atlantic and the west-central Pacific. Interestingly, vast areas over the ocean feature AOD fractions of less than $40 \%$, suggesting a significant contribution of free tropospheric aerosols to the total AOD. These results are qualitatively consistent with the results of Bourgeois et al. (2018) using CALIPSO version 4.1 .

\section{Discussion}

One of the few global satellite-based estimates of lidar ratio is reported in Bréon (2013), who estimated LR utilizing the retrieved scattering phase function at a $180^{\circ}$ angle derived from the Polarization and Directionality of the Earth's Reflectances (POLDER) satellite instrument and a prescribed aerosol model. POLDER LR and CALIOP-SODA (Figs. 910) yield high LR over the coasts of eastern Africa and Eurasia and a notable increase in LR over the Indian Ocean in boreal autumn-winter. In addition, both POLDER and CALIOP-SODA produce LR $<30 \mathrm{sr}$ over the open ocean. Conversely, LRs from POLDER tend to be slightly higher, with a typical range between 30 and $70 \mathrm{sr}$. Bréon (2013) also indicates that because POLDER retrievals rely on scattered photon measurements, LR might be biased low in regions dominated by absorbing aerosol, such as the southeast Atlantic. A somewhat different method of retrieving LR from SODA AOD, documented in Josset et al. (2011), consists of analytically solving the lidar equation. The only avail- 

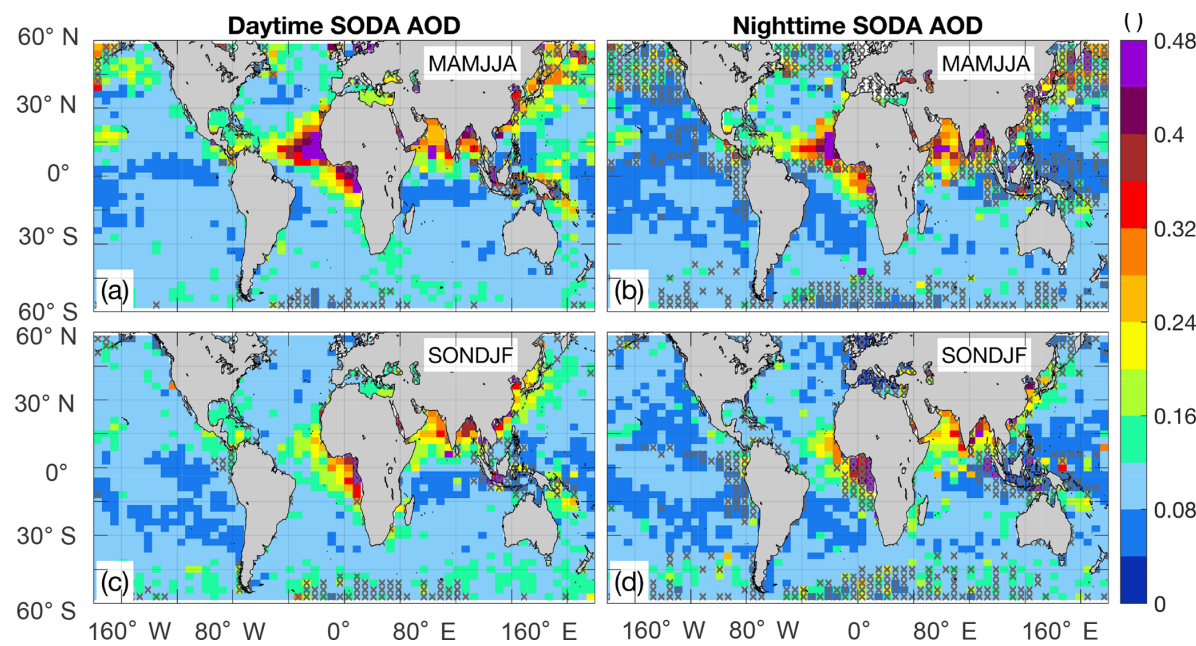

Figure 11. SODA AOD for daytime $(\mathbf{a}, \mathbf{c})$ and nighttime $(\mathbf{b}, \mathbf{d})$ spring-summer (MAMJJA) and autumn-winter (SONDJF). Gray crosses are described in Fig. 9.

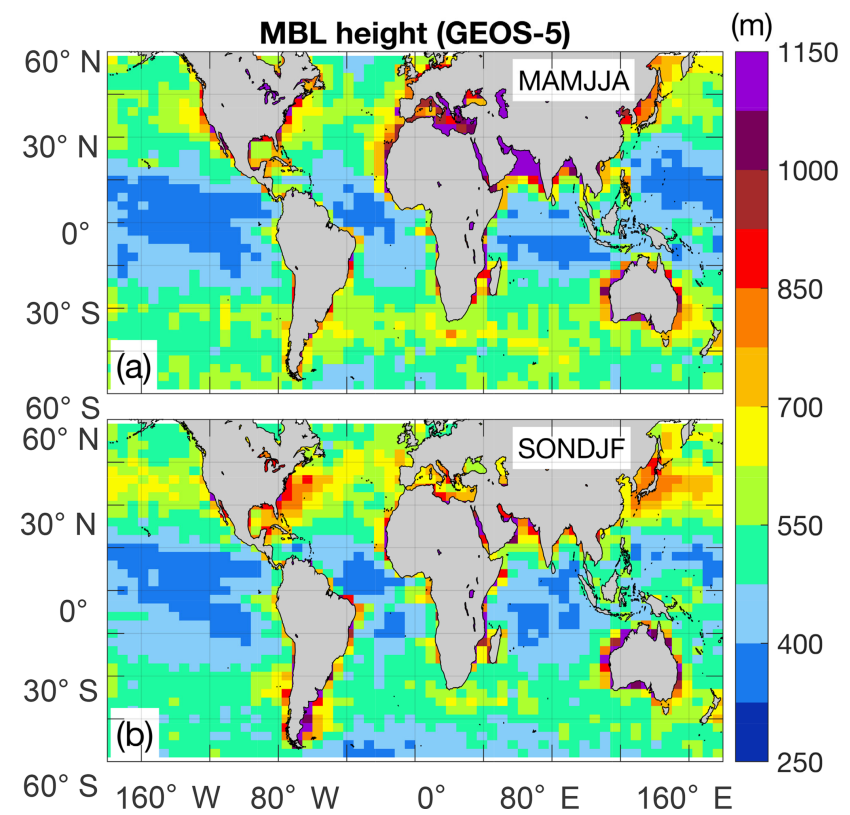

Figure 12. Daytime marine boundary layer height for (a) springsummer and (b) autumn-winter.

able global analysis of LR using the technique in Josset et al. (2011) is documented in Dawson et al. (2015) for maritime aerosols only, reporting values between 20 and $40 \mathrm{sr}$.

As different aerosol types can be, to some extent, characterized by their lidar ratio, the reliability of CALIOP-SODA LR retrievals is qualitatively assessed by analyzing the consistency between the CALIOP-SODA LR spatial pattern and the regional occurrence of aerosol types as well as lidar measurements from several field campaigns over the ocean. Burton et al. (2012), using HSRL measurements over North America and the adjacent Atlantic Ocean, provide the fol- lowing lidar ratios for a number of aerosol types: the highest LRs (45-80 sr) are typically attributed to smoke and urban aerosols, LRs of 25-50 and $40 \mathrm{sr}$ are associated with dust and polluted maritime aerosols (respectively), and maritime aerosols are characterized by lidar ratios of less than $30 \mathrm{sr}$. For simplicity, we will primarily interpret daytime $L_{1 L}$ in Fig. $9 \mathrm{a}$ and $\mathrm{c}$ for the following regions of interest.

\subsection{Southeast Atlantic}

The SODA LR peak in the southeast Atlantic is explained by the well-documented biomass burning season over southern Africa, with massive fire events from May to September during the dry season (Roberts et al., 2009) and smoke being transported offshore by the prevailing winds from July to October (Adebiyi et al., 2015). HSRL airborne measurements collected in September 2016 (Burton et al., 2018) show $532 \mathrm{~nm}$ LRs in the range $58-76 \mathrm{sr}$ in the free troposphere, with CALIOP-SODA yielding values in the lower bound of the HSRL measurements (55-60 sr). In addition, shipborne Raman lidar observations south of the region dominated by biomass burning aerosols $\left(30^{\circ} \mathrm{S}\right.$, near the South African coast) reveal a transition from a lower troposphere dominated by smoke to one mainly composed of maritime aerosols (lidar ratios less than 25 sr; Bohlmann et al., 2018). This southward reduction in LR is reproduced by CALIOPSODA.

\subsection{Mediterranean Sea}

The high spring-summer SODA LR over the Mediterranean Sea $(\sim 50 \mathrm{sr})$ is also expected given the southward pollution transport from Europe, which is maximized in summer in the boundary layer (Duncan and Bey, 2004). Moreover, lidar observations show a maximum dust AOD over the Mediterranean Sea (southern Italy) in summer (Mona 

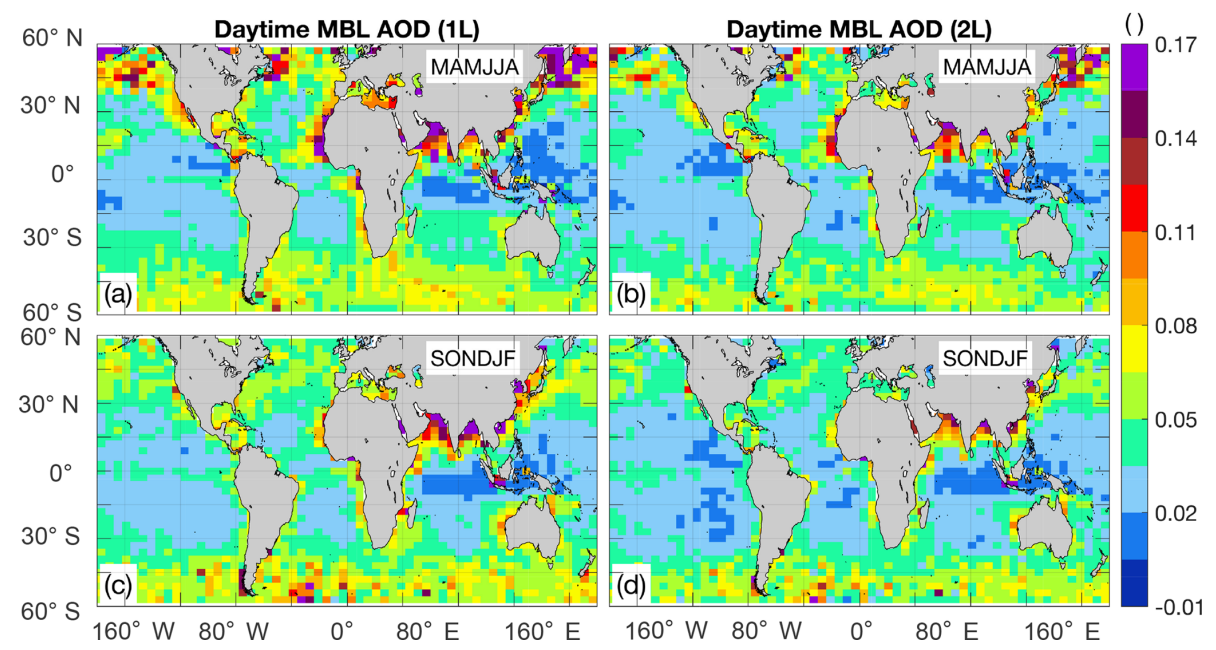

Figure 13. Daytime MBL $532 \mathrm{~nm}$ AOD based on $1 \mathrm{~L}(\mathbf{a}, \mathbf{c})$ and $2 \mathrm{~L}(\mathbf{b}, \mathbf{d})$.
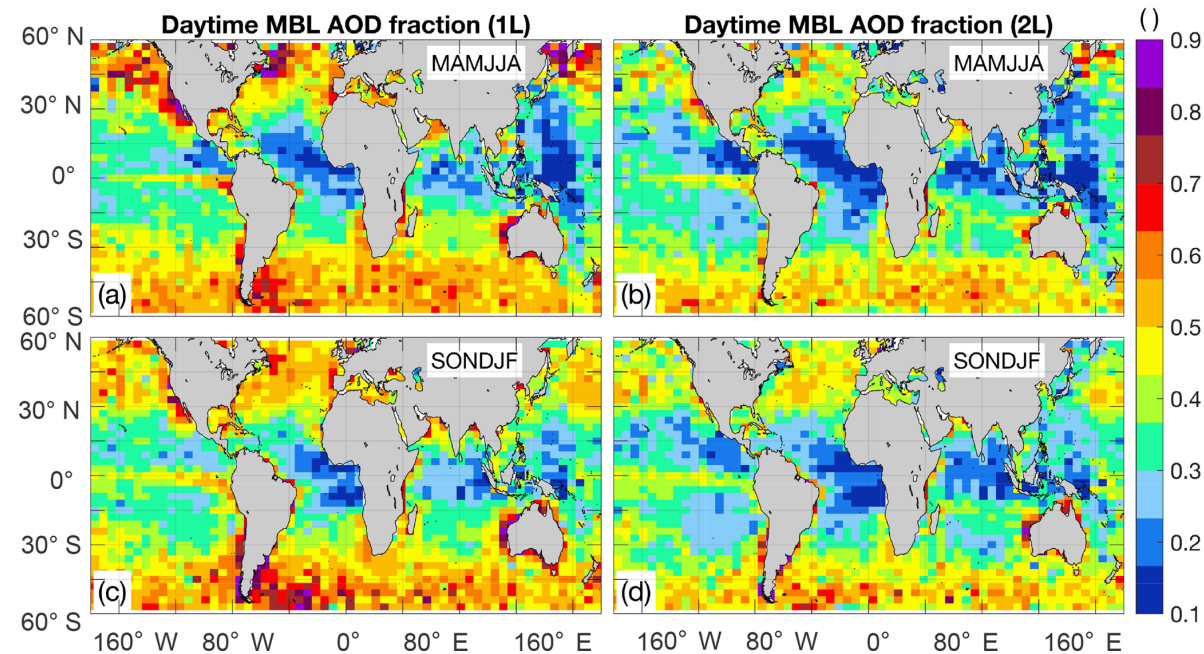

Figure 14. Fraction of daytime AOD contributed by the marine boundary layer.

et al., 2006), in connection with a Saharan dust layer in the free troposphere. The higher presence of pollution and dust in spring would explain the high CALIOP-SODA LR in spring-summer (MAMJJA).

\subsection{Bay of Bengal and western Pacific Ocean}

A major LR maximum in autumn-winter (SONDJF) is observed south of India, over the Bay of Bengal and part of the Arabian Sea. This pattern is concomitant with the pervasive presence of pollution and biomass burning during the winter and pre-monsoon season (October to April; Krishnamurti et al., 2009). In contrast, during the monsoon season (June-September), dust aerosols become the dominant species over the Bay of Bengal (Das et al., 2013), which is manifested in the reduction in SODA LR in spring-summer (MAMJJA). Further east, off the coast of eastern China and
Korea, a semiannual contrast is retrieved by SODA, with maximum LR $>55$ sr for SONDJF. Changes between autumn and spring were also observed over the Korean peninsula in the lidar ratios retrieved with a Raman lidar (Noh et al., 2008), with layer mean of 56 and $63 \mathrm{sr}$ for spring and autumn, respectively, and larger differences in the free troposphere. These changes are thought to be primarily explained by seasonal changes in the composition of dust and smoke.

\subsection{Eastern Pacific and Southern Ocean}

Regions with intermediate CALIOP-SODA LR $(35 \mathrm{sr}<$ $\mathrm{LR}<50 \mathrm{sr}$ ) are located over broad regions of the eastern Pacific and the east coast of North America. These regions are likely influenced by a combination of maritime aerosols and pollution from the continents. It is nevertheless surprising that high SODA lidar ratios are retrieved over rather pristine 
regions, especially over the Southern Ocean, where maritime aerosols are expected to be the dominant aerosol type. A plausible factor that may help reconcile high LR for maritime aerosols is a lidar ratio increase with relative humidity (Ackerman, 1998). Relative humidity could also explain the presence of LR > 30 sr over stratocumulus cloud regimes, where high relative humidity is confined in the boundary layer.

\subsection{Central Pacific and northern Atlantic}

The regions with the lowest LR are located over the tropical Pacific Ocean, where AOD is the lowest (Fig. 11). An unanticipated result is the absence of a zonal band across the Atlantic that could be attributed to the westward transport of Saharan dust across the Atlantic Ocean. Unfortunately, due to the lack of in situ observations along the Saharan dust pathways, the assessment of SODA LR over this region is challenging. Raman lidar data over the eastern Atlantic (Cape Verde), off the coast of western Africa, in spring show dust and smoke in the free troposphere and boundary layer with a mean LR of $54 \mathrm{sr}$ (Tesche et al., 2011) and a dust layer thickness of about $4 \mathrm{~km}$. Over the same region, SODA LR is $40 \mathrm{sr}$, which increases up to $45-50 \mathrm{sr}$ when LR is estimated using the $2 \mathrm{~L}$ assumption. Ground-based lidar observations over the western Atlantic (Barbados, $13.14^{\circ} \mathrm{N}, 59.62^{\circ} \mathrm{W}$ ) in summer reveal the presence of maritime aerosols and dust, with lidar ratios of less than $40 \mathrm{sr}$ in the boundary layer, and pure dust aerosols generally confined to the free troposphere (Groß et al., 2015). This suggests that the relatively low CALIOPSODA LR over the Atlantic basin may be explained by the contribution of maritime aerosols in the boundary layer. A more quantitative assessment, which includes the analysis of specific dust events, is left for future work. Lastly, interpretation of the $1064 \mathrm{~nm}$ CALIOP-SODA is not attempted here due to the lack of independent measurements and calibration uncertainties associated with the use of CALIPSO V3 for deriving SODA AOD. A future release of SODA based on CALIPSO V4 will benefit from the improved calibration of V4, which is estimated to be within $3 \%$ (Vaughan et al., 2019).

An aspect that deserves further discussion is the reliability of SODA AOD, as it is essential for constraining the lidar equation in our study. We find a high linear correlation between SODA and HSRL AOD $(r=0.96)$, with no clear relationship between SODA biases and AOD magnitudes, and a SODA-to-HSRL RMSE comparable to the one estimated between SODA and AERONET in Dawson et al. (2015). The differences between SODA, CALIPSO V4 and MODIS AOD (Figs. 4 and 5) also support inferences based on comparisons between MODIS and CALIPSO Science Team AOD over the ocean (Redemann et al., 2012; Kim et al., 2013). Redemann et al. (2012) and our results both point to an overestimation of CALIPSO V4 AOD over oceanic regions dominated by dust and an underestimation in regions dominated by smoke. However, errors in SODA AOD are plausible, es- pecially when considering the sometimes large differences between SODA and MODIS AOD (>0.06, Fig. 5). To assess the uncertainty in the retrieved CALIOP-SODA LR attributed to errors in SODA AOD, we assume a $\pm 20 \%$ perturbation in SODA AOD and estimated LR. A $20 \%$ AOD error is similar to the $24 \%$ RMSE between SODA and the airborne HSRL AOD (Sect. 4). For one CALIPSO overpass we found that a $20 \%$ higher SODA AOD gives rise to a $5.4 \mathrm{sr}$ increase in lidar ratio, or equivalent to a $14.4 \%$ lidar ratio change relative to the LR constrained with unperturbed AOD. Similarly, a $20 \%$ lower SODA AOD yields a $6.0 \mathrm{sr}$ decrease in lidar ratio $(-16.0 \%)$. These results are analogous to the $\triangle \mathrm{AOD}$ uncertainty of $18 \%$ (for $\mathrm{AOD}=0.15$ ) attributed to a $15 \%$ error in the lidar ratio prescribed by the CALIPSO algorithm, derived using the AOD error equation in Winker et al. (2009).

\section{Concluding remarks}

A total of 1 year of a new CALIOP-based aerosol extinction coefficient and lidar ratio dataset has been presented, with the goal of providing a flexible dataset for climate research as well as independent retrievals that can be helpful for refining CALIPSO Science Team algorithms. The new retrievals build on the CALIPSO V4 total attenuated backscatter and cloud mask data products. However, the method that we used to invert the lidar equation differs fundamentally from the CALIOP standard aerosol product, as it does not rely upon an aerosol classification module to prescribe the lidar ratio. We evaluated CALIOP-SODA AOD, LR and extinction using airborne HSRL retrievals over the western Atlantic, and found excellent agreement, with statistically significant correlations $(r \geq 0.67)$ and biases around $27 \%$ $32 \%$. Given these encouraging results, we envision potential uses of CALIOP-SODA lidar ratios for evaluating CALIOP V4 aerosol properties. This can be carried out similar to Dawson et al. (2015), by stratifying CALIOP-SODA LR as a function of CALIOP V4 aerosol types and their assigned lidar ratio.

Although the retrievals presented here are limited to cloudfree atmospheric columns due to the constraint imposed by SODA AOD, it is possible to adapt the algorithm to make use of above-cloud satellite AOD retrievals (e.g., Jethva et al., 2014; Liu et al., 2015). In this regard, above-cloud AOD using CALIOP can be derived by combining the integrated attenuated backscatter and depolarization ratio ( $\mathrm{Hu}$ et al., 2007; Liu et al., 2015) with corrections for the multiplescattering depolarization relationship implemented by SODA (Deaconu et al., 2017). Efforts to retrieve above-cloud lidar ratio and extinction profiles over the southeast Atlantic using the above-cloud AOD are currently underway (Ferrare et al., 2018). 
CALIOP-SODA 1L retrievals are expected to perform better for relatively homogeneous atmospheric profiles characterized by a single aerosol type. Alternatively, SODA $2 \mathrm{~L}$ retrievals are likely to be advantageous for specific regions where massive aerosol plumes from the continent are transported offshore at high altitudes through convective processes, in such a way that MBL aerosols are detached from the layer above and the assumption MBL LR $=25 \mathrm{sr}$ (maritime) is a good approximation. This is probably the case over the southeast Atlantic during the biomass burning season or for episodic dust transport over the tropical Atlantic. However, the CALIPSO Science Team product will continue providing the best available global dataset for monitoring complex aerosol profiles, continental processes and aerosols in the upper troposphere.

Data availability. CALIPSO version 4.1 is available at https://eosweb.larc.nasa.gov (last access: 17 January 2019) https://doi.org/10.5067/CALIOP/CALIPSO/LID_L2_05kmAProStandard-V4-10 (Vaughan et al., 2019b), and SODA aerosol optical depth is available at http://www.icare.univ-lille1.fr/projects/soda (last access: 27 December 2017; Josset et al., 2015).

Author contributions. MC, RF, DJ and SB developed the algorithms for retrieving aerosol extinction coefficient and lidar ratio, with inputs from DP. DP conducted the analysis and wrote the paper with contributions from all the co-authors.

Competing interests. The authors declare that they have no conflict of interest.

Acknowledgements. This work was funded by the CloudSat and CALIPSO Science Recompete Program NASA award no. NNH16CY04C. The SODA product is developed at the AERIS/ICARE data and services center (http://www.icare.univ-lille1.fr/projects/soda, last access: 27 December 2017) in Lille (France) in the frame of the CALIPSO mission and supported by CNES. The AERIS data infrastructure is greatly acknowledged for data, processing and development supports of the SODA product.

We thank Gregory Schuster for his insightful comments and suggestions and Jacques Pelon for fruitful discussions related to the SODA product and algorithms.

Financial support. This research has been supported by the NASA (grant no. NNH16CY04C).

Review statement. This paper was edited by Ulla Wandinger and reviewed by two anonymous referees.

\section{References}

Ackermann, J.: The Extinction-to-Backscatter Ratio of Tropospheric Aerosol: A Numerical Study, J. Atmos. Ocean. Tech., 15, 1043-1050, https://doi.org/10.1175/15200426(1998)015<1043:TETBRO>2.0.CO;2, 1998.

Adebiyi, A. A., Zuidema, P., and Abel, S. J.: The Convolution of Dynamics and Moisture with the Presence of Shortwave Absorbing Aerosols over the Southeast Atlantic, J. Climate, 28, 1997 2024, https://doi.org/10.1175/JCLI-D-14-00352.1, 2015.

Ansmann, A.: Ground-truth aerosol lidar observations: can the Klett solutions obtained from ground and space be equal for the same aerosol case?, Appl. Optics, 45, 3367-3371, 2006.

Bohlmann, S., Baars, H., Radenz, M., Engelmann, R., and Macke, A.: Ship-borne aerosol profiling with lidar over the Atlantic Ocean: from pure marine conditions to complex dust-smoke mixtures, Atmos. Chem. Phys., 18, 9661-9679, https://doi.org/10.5194/acp-18-9661-2018, 2018.

Bourgeois, Q., Ekman, A. M. L., Renard, J.-B., Krejci, R., Devasthale, A., Bender, F. A.-M., Riipinen, I., Berthet, G., and Tackett, J. L.: How much of the global aerosol optical depth is found in the boundary layer and free troposphere?, Atmos. Chem. Phys., 18, 7709-7720, https://doi.org/10.5194/acp-187709-2018, 2018.

Bréon, F.-M.: Aerosol extinction-to-backscatter ratio derived from passive satellite measurements, Atmos. Chem. Phys., 13, 89478954, https://doi.org/10.5194/acp-13-8947-2013, 2013.

Burton, S. P., Ferrare, R. A., Hostetler, C. A., Hair, J. W., Kittaka, C., Vaughan, M. A., Obland, M. D., Rogers, R. R., Cook, A. L., Harper, D. B., and Remer, L. A.: Using airborne high spectral resolution lidar data to evaluate combined active plus passive retrievals of aerosol extinction profiles, J. Geophys. Res.-Atmos., 115, D00H15, https://doi.org/10.1029/2009jd012130, 2010.

Burton, S. P., Ferrare, R. A., Hostetler, C. A., Hair, J. W., Rogers, R. R., Obland, M. D., Butler, C. F., Cook, A. L., Harper, D. B., and Froyd, K. D.: Aerosol classification using airborne High Spectral Resolution Lidar measurements - methodology and examples, Atmos. Meas. Tech., 5, 73-98, https://doi.org/10.5194/amt-5-732012, 2012.

Burton, S. P., Ferrare, R. A., Vaughan, M. A., Omar, A. H., Rogers, R. R., Hostetler, C. A., and Hair, J. W.: Aerosol classification from airborne HSRL and comparisons with the CALIPSO vertical feature mask, Atmos. Meas. Tech., 6, 13971412, https://doi.org/10.5194/amt-6-1397-2013, 2013.

Burton, S. P., Hostetler, C. A., Cook, A. L., Hair, J. W., Seaman, S. T., Scola, S., Harper, D. B., Smith, J. A., Fenn, M. A., Ferrare, R. A., Saide, P. E., Chemyakin, E. V., and Müller, D.: Calibration of a high spectral resolution lidar using a Michelson interferometer, with data examples from ORACLES, Appl. Optics, 57, 60616075, 2018.

Das, S., Dey, S., Dash, S. K., and Basil, G.: Examining mineral dust transport over the Indian subcontinent using the regional climate model, RegCM4.1, Atmos. Res., 134, 64-76, 2013.

Das, S., Harshvardhan, H., Bian, H., Chin, M., Curci, G., Protonotariou, A. P., Mielonen, T., Zhang, K., Wang, H., and Liu, X.: Biomass burning aerosol transport and vertical distribution over the South African-Atlantic region, J. Geophys. Res.-Atmos., 122, 6391-6415, https://doi.org/10.1002/2016JD026421, 2017.

Dawson, K. W., Meskhidze, N., Josset, D., and Gassó, S.: Spaceborne observations of the lidar ratio of marine aerosols, At- 
mos. Chem. Phys., 15, 3241-3255, https://doi.org/10.5194/acp15-3241-2015, 2015.

Deaconu, L. T., Waquet, F., Josset, D., Ferlay, N., Peers, F., Thieuleux, F., Ducos, F., Pascal, N., Tanré, D., Pelon, J., and Goloub, P.: Consistency of aerosols above clouds characterization from A-Train active and passive measurements, Atmos. Meas. Tech., 10, 3499-3523, https://doi.org/10.5194/amt10-3499-2017, 2017

de Laat, A. T. J., Stein Zweers, D. C. , Boers, R., and Tuinder, O. N. E.: A solar escalator: Observational evidence of the self-lifting of smoke and aerosols by absorption of solar radiation in the February 2009 Australian Black Saturday plume, J. Geophys. Res., 117, D04204, https://doi.org/10.1029/2011JD017016, 2012.

Duncan, B. N. and Bey, I.: A modeling study of the export pathways of pollution from Europe: Seasonal and interannual variations (1987-1997), J. Geophys. Res., 109, D08301, https://doi.org/10.1029/2003JD004079, 2004.

Eloranta, E. W.: High spectral resolution lidar, in: Lidar. RangeResolved Optical Remote Sensing of the Atmosphere, edited by: Weitkamp, C., 143-163, Springer, New York, 2005.

Fernald, F. G.: Analysis of atmospheric lidar observations: Some comments, Appl. Optics, 23, 652-653, https://doi.org/10.1364/AO.23.000652, 1984.

Ferrare, R., Burton, S., Cook, A. L., Harper, D. B., Hostetler, C., Hair, J., Clayton, M., Vaughan, M., Hu, Y., Fenn, M., Josset, D., Redemann, J., and da Silva, A.: CALIOP and Airborne HSRL-2 Measurements of Smoke above low clouds during ORACLES, CloudSat/CALIPSO Annual Science Review, 23-25 April 2018, Boulder, Colorado, USA, 2018.

Gravseth, I. J. and Piepe, B.: CloudSat's return to the A-Train, International Journal of Space Science and Engineering, 1, 410-431, https://doi.org/10.1504/IJSPACESE.2013.059269, 2013.

Groß, S., Esselborn, M., Weinzierl, B., Wirth, M., Fix, A., and Petzold, A.: Aerosol classification by airborne high spectral resolution lidar observations, Atmos. Chem. Phys., 13, 2487-2505, https://doi.org/10.5194/acp-13-2487-2013, 2013.

Groß, S., Freudenthaler, V., Schepanski, K., Toledano, C., Schäfler, A., Ansmann, A., and Weinzierl, B.: Optical properties of long-range transported Saharan dust over Barbados as measured by dual-wavelength depolarization Raman lidar measurements, Atmos. Chem. Phys., 15, 11067-11080, https://doi.org/10.5194/acp-15-11067-2015, 2015.

Haarig, M., Ansmann, A., Gasteiger, J., Kandler, K., Althausen, D., Baars, H., Radenz, M., and Farrell, D. A.: Dry versus wet marine particle optical properties: $\mathrm{RH}$ dependence of depolarization ratio, backscatter, and extinction from multiwavelength lidar measurements during SALTRACE, Atmos. Chem. Phys., 17, 1419914217, https://doi.org/10.5194/acp-17-14199-2017, 2017.

Hair, J. W., Hostetler, C. A., Cook, A. L., Harper, D. B., Ferrare, R. A., Mack, T. L., Welch, W., Izquierdo, L. R., and Hovis, F. E.: Airborne high spectral resolution lidar for pro- filing aerosol optical properties, Appl. Optics, 47, 6734-6752, https://doi.org/10.1364/AO.47.006734, 2008.

Hu, Y., Vaughan, M., Liu, Z., Powell, K., and Rodier, S.: Retrieving optical depths and lidar ratios for transparent layers above opaque water clouds from CALIPSO lidar measurements, IEEE Geosci. Remote Sens. Lett., 4, 523-526, https://doi.org/10.1109/LGRS.2007.901085, 2007.
Itahashi, S., Yumimoto, K., Uno, I., Eguchi, K., Takemura, T., Hara, Y., Shimizu, A., Sugimoto, N., and Liu, Z.: Structure of dust and air pollutant outflow over East Asia in the spring, Geophys. Res. Lett., 37, L20806, https://doi.org/10.1029/2010GL044776, 2010.

Jethva, H., Torres, O., Waquet, F., Chand, D., and Hu, Y.: How do A-train sensors intercompare in the retrieval of above-cloud aerosol optical depth? A case study-based assessment, Geophys. Res. Lett., 41, 186-192, https://doi.org/10.1002/2013GL058405, 2014.

Josset, D., Pelon, J., Protat, A., and Flamant, C.: New approach to determine aerosol optical depth from combined CALIPSO and CloudSat ocean surface echoes, Geophys. Res. Lett., 35, L10805, https://doi.org/10.1029/2008GL033442, 2008.

Josset, D., Pelon, J., and $\mathrm{Hu}, \mathrm{Y}$ : Multi-instrument calibration method based on a multiwavelength ocean surface model, IEEE Geosci. Remote S., 7, 195-199, https://doi.org/10.1109/LGRS.2009.2030906, 2010.

Josset, D., Rogers, R., Pelon, J., Hu, Y., Liu, Z., Omar, A., and Zhai, P.: CALIPSO lidar ratio retrieval over the ocean, Opt. Express, 19, 18696-18706, 2011.

Josset, D., Tanelli, S., Hu, Y., Pelon, J., and Zhai, P.: Analysis of water vapor correction for CloudSat W-band radar, IEEE T. Geosci. Remote, 51, 3812-3825, 2013.

Josset, D., Hou, W., Pelon, J., Hu, Y., Tanelli, S., Ferrare, R., Burton, S., and Pascal, N.: Ocean and polarization observations from active remote sensing: atmospheric and ocean science applications, Proc. SPIE 9459, Ocean Sensing and Monitoring VII, 94590N, https://doi.org/10.1117/12.2181544, 2015.

Khaykin, S. M., Godin-Beekmann, S., Hauchecorne, A., Pelon, J., Ravetta, F., and Keckhut, P.: Stratospheric smoke with unprecedentedly high backscatter observed by lidars above southern France, Geophys. Res. Lett., 45, 1639-1646, https://doi.org/10.1002/2017GL076763, 2018.

Kim, M.-H., Kim, S.-W., Yoon, S.-C., and Omar, A. H.: Comparison of aerosol optical depth between CALIOP and MODIS-Aqua for CALIOP aerosol subtypes over the ocean, J. Geophys. Res.-Atmos., 118, 13241-13252, https://doi.org/10.1002/2013JD019527, 2013.

Kim, M.-H., Omar, A. H., Vaughan, M. A., Winker, D. M., Trepte, C. R., Hu, Y., Liu, Z., and Kim, S.-W.: Quantifying the low bias of CALIPSO's column aerosol optical depth due to undetected aerosol layers, J. Geophys. Res.-Atmos., 122, 1098-1113, https://doi.org/10.1002/2016JD025797, 2017.

Kim, M.-H., Omar, A. H., Tackett, J. L., Vaughan, M. A., Winker, D. M., Trepte, C. R., Hu, Y., Liu, Z., Poole, L. R., Pitts, M. C., Kar, J., and Magill, B. E.: The CALIPSO version 4 automated aerosol classification and lidar ratio selection algorithm, Atmos. Meas. Tech., 11, 6107-6135, https://doi.org/10.5194/amt11-6107-2018, 2018.

Kittaka, C., Winker, D. M., Vaughan, M. A., Omar, A., and Remer, L. A.: Intercomparison of column aerosol optical depths from CALIPSO and MODIS-Aqua, Atmos. Meas. Tech., 4, 131-141, https://doi.org/10.5194/amt-4-131-2011, 2011.

Koffi, B., Schulz, M., Bréon, F.-M., Dentener, F., Steensen, B. M., Griesfeller, J., Winker, D., Balkanski, Y., Bauer, S. E., Bellouin, N., Berntsen, T., Bian, H., Chin, M., Diehl, T., Easter, R., Ghan, S., Hauglustaine, D. A., Iversen, T., Kirkevag, A., Liu, X., Lohmann, U., Myhre, G., Rasch, P., Seland, O., Skeie, 
R. B., Steenrod, S. D., Stier, P., Tackett, J., Takemura, T., Tsigaridis, K., Vuolo, M. R., Yoon, J., and Zhang, K.: Evaluation of the aerosol vertical distribution in global aerosol models through comparison against CALIOP measurements: AeroCom phase II results, J. Geophys. Res.-Atmos., 121, 7254-7283, https://doi.org/10.1002/2015JD024639, 2016.

Krishnamurti, T. N., Chakraborty, A., Martin, A., Lau, W. K., Kim, K.-M., Sud, Y., and Walker, G.: Impact of Arabian Sea pollution on the Bay of Bengal winter monsoon rains, J. Geophys. Res., 114, D06213, https://doi.org/10.1029/2008JD010679, 2009.

Levy, R. C., Mattoo, S., Munchak, L. A., Remer, L. A., Sayer, A. M., Patadia, F., and Hsu, N. C.: The Collection 6 MODIS aerosol products over land and ocean, Atmos. Meas. Tech., 6, 29893034, https://doi.org/10.5194/amt-6-2989-2013, 2013.

Liu, Z., Omar, A., Vaughan, M., Hair, J., Kittaka, C., Hu, Y., Powell, K., Trepte, C., Winker, D., Hostetler, C., Ferrare, R., and Pierce, R.: CALIPSO lidar observations of the optical properties of Saharan dust: A case study of long-range transport, J. Geophys. Res., 113, D07207, https://doi.org/10.1029/2007JD008878, 2008.

Liu, Z., Winker, D., Omar, A., Vaughan, M., Kar, J., Trepte, C., $\mathrm{Hu}$, Y., and Schuster, G.: Evaluation of CALIOP $532 \mathrm{~nm}$ aerosol optical depth over opaque water clouds, Atmos. Chem. Phys., 15, 1265-1288, https://doi.org/10.5194/acp-15-1265-2015, 2015.

Liu, Z., Kar, J., Zeng, S., Tackett, J., Vaughan, M., Avery, M., Pelon, J., Getzewich, B., Lee, K.-P., Magill, B., Omar, A., Lucker, P., Trepte, C., and Winker, D.: Discriminating between clouds and aerosols in the CALIOP version 4.1 data products, Atmos. Meas. Tech., 12, 703-734, https://doi.org/10.5194/amt-12-7032019, 2019.

McGrath-Spangler, E. L. and Denning, A. S.: Global seasonal variations of midday planetary boundary layer depth from CALIPSO space-borne LIDAR, J. Geophys. Res.-Atmos., 118, 1226-1233, https://doi.org/10.1002/jgrd.50198, 2013.

McGrath-Spangler, E. L. and Molod, A.: Comparison of GEOS5 AGCM planetary boundary layer depths computed with various definitions, Atmos. Chem. Phys., 14, 6717-6727, https://doi.org/10.5194/acp-14-6717-2014, 2014.

Mona, L., Amodeo, A., Pandolfi, M., and Pappalardo, G.: Saharan dust intrusions in the Mediterranean area: Three years of Raman lidar measurements, J. Geophys. Res., 111, D16203, https://doi.org/10.1029/2005JD006569, 2006.

Müller, D., Ansmann, A., Mattis, I., Tesche, M., Wandinger, U., Althausen, D., and Pisani, G.: Aerosol-type-dependent lidar ratios observed with Raman lidar, J. Geophys. Res., 112, D16202, https://doi.org/10.1029/2006JD008292, 2007.

Noh, Y. M., Kima, Y. J., and Müller, D.: Seasonal characteristics of lidar ratios measured with a Raman lidar at Gwangju, Korea in spring and autumn, Atmos. Environ., 42, 2208-2224, https://doi.org/10.1016/j.atmosenv.2007.11.045, 2008.

Nowottnick, E. P., Colarco, P. R., Welton, E. J., and da Silva, A.: Use of the CALIOP vertical feature mask for evaluating global aerosol models, Atmos. Meas. Tech., 8, 3647-3669, https://doi.org/10.5194/amt-8-3647-2015, 2015.

Omar, A. H., Winker, D. M., Vaughan, M. A., Hu, Y., Trepte, C. R., Ferrare, R. A., Lee, K., Hostetler, C. A., Kittaka, C., Rogers, R. R., Kuehn, R. E., and Liu, Z.: The CALIPSO Automated Aerosol Classification and Lidar Ratio Selec- tion Algorithm, J. Atmos. Ocean. Tech., 26, 1994-2014, https://doi.org/10.1175/2009JTECHA1231.1, 2009.

Redemann, J., Vaughan, M. A., Zhang, Q., Shinozuka, Y., Russell, P. B., Livingston, J. M., Kacenelenbogen, M., and Remer, L. A.: The comparison of MODIS-Aqua (C5) and CALIOP (V2 \& V3) aerosol optical depth, Atmos. Chem. Phys., 12, 3025-3043, https://doi.org/10.5194/acp-12-3025-2012, 2012.

Roberts, G., Wooster, M. J., and Lagoudakis, E.: Annual and diurnal african biomass burning temporal dynamics, Biogeosciences, 6 , 849-866, https://doi.org/10.5194/bg-6-849-2009, 2009.

Rogers, R. R., Hair, J. W., Hostetler, C. A., Ferrare, R. A., Obland, M. D., Cook, A. L., Harper, D. B., Burton, S. P., Shinozuka, Y., McNaughton, C. S., Clarke, A. D., Redemann, J., Russell, P. B., Livingston, J. M., and Kleinman, L. I.: NASA LaRC airborne high spectral resolution lidar aerosol measurements during MILAGRO: observations and validation, Atmos. Chem. Phys., 9, 4811-4826, https://doi.org/10.5194/acp-9-4811-2009, 2009.

Rogers, R. R., Vaughan, M. A., Hostetler, C. A., Burton, S. P., Ferrare, R. A., Young, S. A., Hair, J. W., Obland, M. D., Harper, D. B., Cook, A. L., and Winker, D. M.: Looking through the haze: evaluating the CALIPSO level 2 aerosol optical depth using airborne high spectral resolution lidar data, Atmos. Meas. Tech., 7, 4317-4340, https://doi.org/10.5194/amt-7-4317-2014, 2014.

Royer, P., Raut, J.-C., Ajello, G., Berthier, S., and Chazette, P.: Synergy between CALIOP and MODIS instruments for aerosol monitoring: application to the Po Valley, Atmos. Meas. Tech., 3, 893907, https://doi.org/10.5194/amt-3-893-2010, 2010.

Sawamura, P., Moore, R. H., Burton, S. P., Chemyakin, E., Müller, D., Kolgotin, A., Ferrare, R. A., Hostetler, C. A., Ziemba, L. D., Beyersdorf, A. J., and Anderson, B. E.: HSRL-2 aerosol optical measurements and microphysical retrievals vs. airborne in situ measurements during DISCOVER-AQ 2013: an intercomparison study, Atmos. Chem. Phys., 17, 7229-7243, https://doi.org/10.5194/acp-17-7229-2017, 2017.

Schuster, G. L., Vaughan, M., MacDonnell, D., Su, W., Winker, D., Dubovik, O., Lapyonok, T., and Trepte, C.: Comparison of CALIPSO aerosol optical depth retrievals to AERONET measurements, and a climatology for the lidar ratio of dust, Atmos. Chem. Phys., 12, 7431-7452, https://doi.org/10.5194/acp12-7431-2012, 2012.

Tesche, M., Gross, S., Ansmann, A., Müller, D., Althausen, D., Freudenthaler, V., and Esselborn, M.: Profiling of Saha- ran dust and biomass-burning smoke with multiwavelength polarization Raman lidar at Cape Verde, Tellus, B63, 649-676, https://doi.org/10.1111/j.1600-0889.2011.00548.x, 2011.

Thorsen, T. J., Ferrare, R. A, Hostetler, C. A., Vaughan, M. A., and $\mathrm{Fu}, \mathrm{Q}$.: The impact of lidar detection sensitivity on assessing aerosol direct radiative e?ects, Geophys. Res. Lett., 44, 90599067, https://doi.org/10.1002/2017GL074521, 2017.

Toth, T. D., Campbell, J. R., Reid, J. S., Tackett, J. L., Vaughan, M. A., Zhang, J., and Marquis, J. W.: Minimum aerosol layer detection sensitivities and their subsequent impacts on aerosol optical thickness retrievals in CALIPSO level 2 data products, Atmos. Meas. Tech., 11, 499-514, https://doi.org/10.5194/amt11-499-2018, 2018.

Uno, I., Eguchi, K., Yumimoto, K., Liu, Z., Hara, Y., Sugimoto, N., Shimizu, A., and Takemura, T.: Large Asian dust layers continuously reached North America in April 2010, Atmos. 
Chem. Phys., 11, 7333-7341, https://doi.org/10.5194/acp-117333-2011, 2011.

Várnai, T. and Marshak, A.: Global CALIPSO observations of aerosol changes near clouds, IEEE Geosci. Remote S., 8, 19-23, 2011.

Vaughan, M., Winker, D. M., and Powell, K. A.: CALIOP algorithm theoretical basis document, Part 2: Feature detection and layer properties algorithms, NASA Langley Research Center, Document PC-SCI-202 Part 2, 87 p., available at: https://www-calipso.larc.nasa.gov/resources/pdfs/ PC-SCI-202_Part2_rev1x01.pdf (last access: 13 March 2019), 2005.

Vaughan, M. A., Powell, K. A., Winker, D. M., Hostetler, C. A., Kuehn, R. E., Hunt, W. H., Getzewich, B. J., Young, S. A., Liu, Z., and McGill, M. J.: Fully Automated Detection of Cloud and Aerosol Layers in the CALIPSO Lidar Measurements, J. Atmos. Ocean. Tech., 26, 2034-2050, https://doi.org/10.1175/2009JTECHA1228.1, 2009.

Vaughan, M. A., Liu, Z., McGill, M. J., Hu, Y., and Obland, M. D.: On the spectral dependence of backscatter from cirrus clouds: Assessing CALIOP's 1064m calibration assumptions using cloud physics lidar measurements, J. Geophys. Res., 115, D14206, https://doi.org/10.1029/2009JD013086, 2010.

Vaughan, M., Garnier, A., Josset, D., Avery, M., Lee, K.-P., Liu, Z., Hunt, W., Pelon, J., Hu, Y., Burton, S., Hair, J., Tackett, J. L., Getzewich, B., Kar, J., and Rodier, S.: CALIPSO lidar calibration at $1064 \mathrm{~nm}$ : version 4 algorithm, Atmos. Meas. Tech., 12, 51-82, https://doi.org/10.5194/amt-12-51-2019, 2019a.

Vaughan, M., Pitts, M., Trepte, C., Winker, D., Detweiler, P., Garnier, A., Getzewich, B., Hunt, W., Lambeth, J., Lee, K.-P., Lucker, P., Murray, T., Rodier, S., Tremas, T., Bazureau, A., and Pelon, J.: Cloud-Aerosol LIDAR Infrared Pathfinder Satellite Observations (CALIPSO) data management system data products catalog, Release 4.40, NASA Langley Research Center Document PC-SCI-503, 173 pp., https://doi.org/10.5067/CALIOP/CALIPSO/LID_L2_05kmAProStandard-V4-10, available at: https://www-calipso.larc.nasa. gov/products/CALIPSO_DPC_Rev4x40.pdf, last access: 8 April 2019b. von Engeln, A. and Teixeira, J.: A Planetary Boundary Layer Height Climatology Derived from ECMWF Reanalysis Data, J. Climate, 26, 6575-6590, https://doi.org/10.1175/JCLI-D-12$00385.1,2013$.

Winker, D. M., Vaughan, M. A., Omar, A., Hu, Y., Powell, K. A., Liu, Z., Hunt, W. H., and Young, S. A.: Overview of the CALIPSO Mission and CALIOP Data Processing Algorithms, J. Atmos. Ocean. Tech., 26, 2310-2323, https://doi.org/10.1175/2009JTECHA1281.1, 2009.

Winker, D. M., Pelon, J., Coakley, J. A., Ackerman, S. A., Charlson, R. J., Colarco, P. R., Flamant, P., Fu, Q., Hoff, R. M., Kittaka, C., Kubar, T. L., Le Treut, H., Mccormick, M. P., Mégie, G., Poole, L., Powell, K., Trepte, C., Vaughan, M. A., and Wielicki, B. A.: The CALIPSO Mission: A global 3D view of aerosols and clouds, B. Am. Meteorol. Soc., 91, 1211-1229, https://doi.org/10.1175/2010BAMS3009.1, 2010.

Winker, D. M., Tackett, J. L., Getzewich, B. J., Liu, Z., Vaughan, M. A., and Rogers, R. R.: The global 3-D distribution of tropospheric aerosols as characterized by CALIOP, Atmos. Chem. Phys., 13, 3345-3361, https://doi.org/10.5194/acp-133345-2013, 2013.

Yu, H., Chin, M., Winker, D. M., Omar, A. H., Liu, Z., Kittaka, C., and Diehl, T.: Global view of aerosol vertical distributions from CALIPSO lidar measurements and GOCART simulations: Regional and seasonal variations, J. Geophys. Res., 115, D00H30, https://doi.org/10.1029/2009JD013364, 2010.

Yu, H., Chin, M., Yuan, T., Bian, H., Remer, L. A., Prospero, J. M., Omar, A., Winker, D., Yang, Y., Zhang, Y., Zhang, Z., and Zhao, C.: The Fertilizing Role of African Dust in the Amazon Rainforest: A First Multiyear Assessment Based on CALIPSO Lidar Observations, Geophys. Res. Lett., 42, 1984 1991, https://doi.org/10.1002/2015GL063040, 2015. 